\section{Early Environmental Field Research Career Exploration: An Analysis of Impacts on Precollege Apprentices}

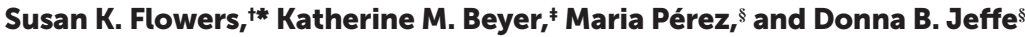

'Tyson Research Center, Washington University in St. Louis, Eureka, MO 63025; 'Educational Visions, St. Louis, MO 63104; \$School of Medicine, Washington University in St. Louis, St. Louis, MO 63110

\begin{abstract}
Research apprenticeships offer opportunities for deep understanding of scientific practice, transparency about research careers, and possible transformational effects on precollege youth. We examined two consecutive field-based environmental biology apprenticeship programs designed to deliver realistic career exploration and connections to research scientists. The Shaw Institute for Field Training (SIFT) program combines introductory fieldskills training with research assistance opportunities, and the subsequent Tyson Environmental Research Fellowships (TERF) program provides immersive internships on university field station-based research teams. In a longitudinal mixed-methods study grounded in social cognitive career theory, changes in youth perspectives were measured during program progression from 10th grade through college, evaluating the efficacy of encouraging career path entry. Results indicate SIFT provided self-knowledge and career perspectives more aligned with reality. During SIFT, differences were found between SIFT-only participants compared with those who progressed to TERF. Transition from educational activities to fieldwork with scientists was a pivotal moment at which data showed decreased or increased interest and confidence. Continuation to TERF provided deeper relationships with role models who gave essential early-career support. Our study indicates the two-stage apprenticeship structure influenced persistence in pursuit of an environmental research career pathway. Recommendations for other precollege environmental career-exploration programs are presented.
\end{abstract}

\section{INTRODUCTION}

Facilitating early access to the scientific community is important for encouraging participation in science, technology, engineering, and mathematics (STEM) research careers and fostering persistence in that career pathway. For STEM engagement in higher education and the workforce to succeed, youth need exposure to role models and connection with mentors who can show them that a STEM career path is attainable (Garces and Espinosa, 2013). Youth-scientist relationships within research apprenticeship programs can provide critical transparency about professional research communities. Furthermore, the informal learning environment within mentored research experiences informs true understanding of the practice of science and may positively influence persistence in the career pathway. This study focused on environmental biology field research career exploration and how immersive precollege apprenticeship programs might stimulate or sustain early interest and provide a clear career pathway. We sought to determine the extent to which two such programs were effective at making an environmental field science career attainable, explicitly capturing how participation affected youth perspectives on the career over time and what the outcomes were in terms of execution of specific career progression steps.
Michele Shuster, Monitoring Editor Submitted December 3, 2015; Revised August 25, 2016; Accepted August 25, 2016

CBE Life Sci Educ December 1, 2016 15:ar67 DOI:10.1187/cbe.15-11-0230

*Address correspondence to: Susan K. Flowers (flowers(awustl.edu).

(c) 2016 S. K. Flowers et al. CBE-Life Sciences Education ๔ 2016 The American Society for Cell Biology. This article is distributed by The American Society for Cell Biology under license from the author(s). It is available to the public under an Attribution-Noncommercial-Share Alike 3.0 Unported Creative Commons License (http://creativecommons.org/licenses/ by-nc-sa/3.0)

"ASCB®" and "The American Society for Cell Biology $\AA^{\circledR}$ are registered trademarks of The American Society for Cell Biology. 
Collins et al. (1989, 1991) coined the term "cognitive apprenticeship" to explain the inherent learning potential when traditional apprenticeship practices are brought into a precollege educational setting. Barab and Hay (2001) explain that cognitive apprenticeship includes "(1) the development of learning contexts that model proficiency, (2) providing coaching and scaffolding as students become immersed in authentic activities, (3) slowly removing scaffolding as students develop competence, and (4) providing opportunity for independent practice so that students gain an appreciation of the use of domain-related principles across multiple contexts" (p. 72).

Providing high school youth with supported progression within a research apprenticeship program can give them a more complete and accurate picture of career directions. High school apprentices gain an understanding of science as a cumulative body of work, the collaborative roles within a research community, and the uncertainty of the research endeavor (Richmond and Kurth, 1999). Internships with strong mentoring relationships help adolescent youth form career-relevant self-images and make career plans (Packard and Nguyen, 2003). In one youth apprentice case, interactions with the mentoring scientist, especially field-based conversations, and having the opportunity to reflect on the experience appeared important for acquiring an enhanced view of the scientific research endeavor (Bell et al., 2003). The apprenticeship programs described below were specifically designed to include 1) authentic realworld context, 2) scaffolding of direct experience, 3) multiple and sustained mentoring interactions with scientists, and 4) structures for personal reflection on the experience.

The Shaw Institute for Field Training (SIFT) is an introductory field-skills training program that engages 10th and 11th graders in scientific exploration of the natural world at a 2440acre nature reserve located outside a midwestern metropolitan area of the United States. It includes outdoor safety training, basic techniques for assessing terrestrial and aquatic ecosystems, and paid opportunities to assist scientists with fieldwork at the nature reserve and a nearby 2000-acre university environmental field station. SIFT is marketed as an environmental biology career-exploration experience, and program applicants are recruited through targeted communications to high school science teachers and youth program coordinators. Accepted participants come from a variety of urban, suburban, and rural communities, including diverse socioeconomic levels and ethnic identities. SIFTers are selected based on strength of teacher recommendations and short responses to questions about their interest in environmental field research, and with attention to gender and ethnic representation across the metropolitan region. To encourage application by youth outside the top tier of academic performance, transcripts and test scores are specifically not requested. The 5-day SIFT training session takes place in June and includes one overnight stay. After training, SIFTers may sign up for paid half-day or full-day work opportunities depending on their interest. Projects are offered on weekdays throughout the summer and on weekends and school breaks during the following academic year. While no formal mentoring training is provided, SIFT staff communicate with participating local university or nature reserve-based scientists to make sure research support tasks are matched to SIFTer skill level and that research overviews are easily understood. SIFTers come together for additional season-specific field training activities during a fall Saturday in September, a winter weekend overnight in January, and a spring Saturday in March. Throughout the program SIFT staff facilitate group discussion to assist participants in active reflection about their experiences. All SIFTers are encouraged to apply to the second stage program if they have continued interest in environmental field research at the end of SIFT.

The Tyson Environmental Research Fellowships (TERF) is a more advanced field research internship program that provides a competitively selected group of 11 th and 12th grade SIFT graduates with an immersive and extended work experience on current research projects at the university field station, as well as training in scientific communication. They are selected based on observed engagement during the SIFT training activities, positive feedback from the scientists hosting work projects, and their personal statements about future education and career interests. Over a minimum of 4 weeks in June or July, TERFers work side by side with research scientists at all levels, including near-peer undergraduate students, graduate students, postdoctoral researchers, technicians, staff scientists, and university faculty. TERF is modeled on the field station's undergraduate research fellowship program and, in addition to fieldwork, includes research team meetings, journal article discussion, visiting scientist seminars, and stipend support. Weekly discussion is facilitated by TERF staff to help TERFers process the intense summer experience and provide a forum for peer support. TERF staff also check in with the mentoring scientists throughout the field season. During fall and winter of the following academic year, TERFers work on scientific posters under the guidance of their summer mentors and the TERF staff. They present their posters at the university undergraduate research symposium in October and a TERF symposium at the field station in January. (The SIFT and TERF programs are described in more detail in Flowers and Beyer, 2016.)

The SIFT and TERF model integrates three key aspects of research apprenticeships revealed in literature review by Sadler et al. (2010). First, the length of research experience matters, as apprentices need time to become comfortable in the setting and to grasp the research being conducted. SIFT provides multiple exploratory experiences assisting on research projects, and TERF provides for immersion in those same projects, with the extended experience deepening understanding over time. Second, apprenticeship program impacts are enhanced by supplementing research activities with ways for apprentices to make connections between their experiences and their emerging understandings. Both programs have significant time dedicated to self-reflective activities to help the youth make sense of their participation. Third, learning gains may be limited if the apprenticeship experience does not evolve to include more intellectually demanding practices, such as data analysis and hypothesizing. SIFTers develop short presentations of their own field research projects; they share insights from their work with scientists; and, if they move on to TERF, they are mentored in development and presentation of scientific research posters based on analyses of data they helped collect.

The SIFT and TERF programs are independent from formal schooling, and in both programs, the youth have the opportunity to assist career scientists one-on-one with real, in-progress environmental biology research projects. These programs exemplify situated learning within a community of practice in 
which "the increasing participation of newcomers in ongoing practice shapes their gradual transformation into oldtimers" (Lave, 1991, p. 72). The two-stage model includes features that Lave has suggested are "characteristic of communities of practice that reproduce themselves successfully." Precollege youth get "comprehensive goals" in their initial exploration of field skills, learning why scientists use particular techniques in the field and what results they expect. The immediate use of new skills in authentic data collection and analyses and the overviews of research projects provided by the scientists provide "an initial view of the whole." SIFTers see TERFers in the field with some of these same research scientists, making the progression through to the next stage of the career-exploration process visible and doable. Participating on research projects provides interactions with multiple levels of scientists, from undergraduates to faculty, all working within a field station community. This work "within the multiply structured field of mature practice with near peers and mature practitioners" provides for a truly transparent career-exploration experience (Lave, 1991, p. 72). The research presented here focuses on SIFT and TERF participants' experiences as they progressed into a professional environmental biology research community and how their experiences may have influenced their thinking about future career paths. As the primary goal of running the SIFT and TERF programs is to encourage the entry of more youth into the environmental biology research career pathway, our research aim was to evaluate how well the programs actually accomplish this goal.

\section{Research Overview}

To evaluate the extent to which SIFT and TERF are effective at encouraging entry into the environmental field research career pathway, we developed a longitudinal mixed-methods study (Lieber, 2009) to assess participants' interest in environmental field science activities and careers, their confidence in their ability to successfully pursue this type of career, and the personal contexts that might affect their pursuit (perceived social and economic supports and barriers). Derived from Bandura's social cognitive theory (1986), Lent et al.'s $(1994,2000)$ social cognitive career theory provides a framework for this kind of assessment. As Quimby et al. (2007a) have explained, social cognitive career theory.

illustrates the interplay of personal, environmental, and behavioral influences on career development and focuses on processes by which individuals (a) develop academic and career interests, (b) create academic and vocational plans, and (c) attain varying levels of performance and persistence in educational and career pursuits. (p. 44)

It was important to consider the longer-term effects that participation may have had on the youth, as some science-enrichment program impacts may not manifest until participants have separated from the experiences and had time to reflect further (Stake and Mares, 2005). Consequently, follow-up measures of reflective thinking were implemented, and documentation of specific courses of action toward an environmental STEM career path were also obtained. Our study was not experimental, as longitudinal data collection from a control group was not feasible.
We used mixed methods to capture participant thinking and/ or behavior in differing formats, giving us the opportunity to triangulate emerging patterns and findings (Miles and Huberman, 1994). Data collected through one method were used to elaborate, corroborate, or expand on interpretations from data collected through another method (Lieber, 2009) and also to present the multiple realities of the varying participants in the research context (Lincoln, 1990). Our sources of data included two types of participant surveys. The quantitative data derived from a repeated-measures environmental science career interest survey and repeated program climate surveys were contextualized by the qualitative data derived from open-ended reflective survey responses. (Examples of the assessment tools are included in the Supplemental Material.) During the study period, information gained from quantitative and qualitative data sources was shared with the program staff and mentoring scientists to inform refinement in youth-mentoring strategies and program activities. Text-based data were analyzed yearly by coding similar responses to identify emerging themes in the participant experience. At the end of the study period, results of the statistical analysis of the quantitative data were contextualized with themes that emerged using qualitative data analytical techniques.

\section{METHODS \\ Participants}

The minor youth participants and their parents/guardians provided informed consent for their participation in a longitudinal research study before the start of SIFT. Each study cohort included participants who began the program series together in a particular year. Cohort 1 started in 2008 with 51 participants, cohort 2 started in 2009 with 63 participants, cohort 3 started in 2010 with 48 participants, and cohort 4 started in 2011 with 58 participants. The youth came from a wide cross-section of a major metropolitan community and its surrounding areas, representing 51 different high schools (public, private, parochial) and home school populations. Geographic distribution based on school location was $50 \%$ suburban, $29 \%$ urban, and $21 \%$ rural. The gender identity within the group was $69 \%$ female and $31 \%$ male. The ethnic identity of the group was 58\% European American/white, 22\% East Asian/Indian, 18\% African American/Black, and 2\% Latino/Hispanic. At baseline, youth were a mean age of 15.7 years ( $S D=0.68$, age range: $14-17$ ), and the majority had just completed the 10th grade of high school (74\%).

The response size varied for particular instruments due to intermittent youth participation in the data-collection methods. Youth participants were given multiple opportunities to respond to surveys on paper and through online data-encrypted survey software. The study participants for the data reported here were a subset from cohorts $1-4$. The youth included in the analysis of the environmental science career interest survey were a subgroup who responded to at least the first three measures (pre-, mid-, immediately post-SIFT; $N=121$ ) and a further subset who went on to complete a fourth measure (immediately post-TERF; $n=51$ ).

\section{Analytical Procedures}

Environmental Science Career Interest Survey. The interest survey is based on a previously validated instrument adapted with the permission of the originating researchers 
(Quimby et al., 2007a) and consisting of five- and 10-point Likert-scaled level of agreement items. It provides a measure of cognitive (self-efficacy [belief in ability to succeed, confidence] and outcome expectations [expected consequences or rewards of specific courses of action]), contextual (role model influence, social supports, and perceived barriers), and outcome (interest in environmental science) variables (Quimby et al., 2007a,b). While the survey was originally used to assess youth interest in environmental science careers at a single time point, we used it to measure the changes in youth participants' thinking during sequential, immersive environmental research career apprenticeship programs. Potential college majors and demographic questions about age, gender, race/ethnicity, cohort, and year in school were included at baseline. The instrument items are organized into the following survey sections:

A. Interest in environmental science activities, for example, collaborating on research involving ecological or environmental issues;

B. Confidence in environmental science activities, for example, confidence in collaborating on research involving ecological or environmental issues;

C. Confidence in college degree steps, for example, completion of course requirements for a science major with a grade of "B" or better;

D. Importance of desired career outcomes, for example, receive a job offer quickly;

E. Agreement that an environmental science degree will allow the achievement of desired career outcomes, for example, will receive an environmental science job offer quickly;

F. Perception of barriers to the pursuit of an environmental science career, for example, lack of financial and/or social support system;
G. Confidence in overcoming barriers to the pursuit of an environmental science career, for example, will find way around lack of financial and/or social support system; and

H. Perception of social support for the pursuit of an environmental science career path, for example, have support for this pursuit from important people within one's personal life.

A diagram connecting the survey sections to the interrelating domains of cognitive, contextual, and outcome variables in social cognitive career theory is presented in Figure 1.

We examined the factor structure of each survey section at baseline using exploratory principal components analysis with varimax rotation for the purpose of data reduction. We used Lautenschlager's (1989) parallel analysis criteria to determine the number of factors and Cronbach's alpha to measure the internal consistency of items on each measure (Bravo and Potvin, 1991). We retained items that loaded $>0.600$ on a single factor and did not load $>0.400$ on more than one factor. Repeated-measures analyses of variance (RM-ANOVAs) examined change over time in each newly developed environmental science career interest factor during the first three time points (pre-, mid-, and post-SIFT). Separate RM-ANOVAs also examined this same data set to determine whether youth who only completed SIFT (SIFT-only) reported different scores over time as compared with youth who went on to TERF (future-TERF). Also, in the subset of youth program participants who went on to TERF following SIFT completion (SIFT+TERF), separate RM-ANOVAs were used across all four time points (pre-midpost surveys for SIFT plus post-TERF) to determine significant changes in environmental science career interest factors over time. These analyses were performed using IBM SPSS Statistics, version 22.0 .

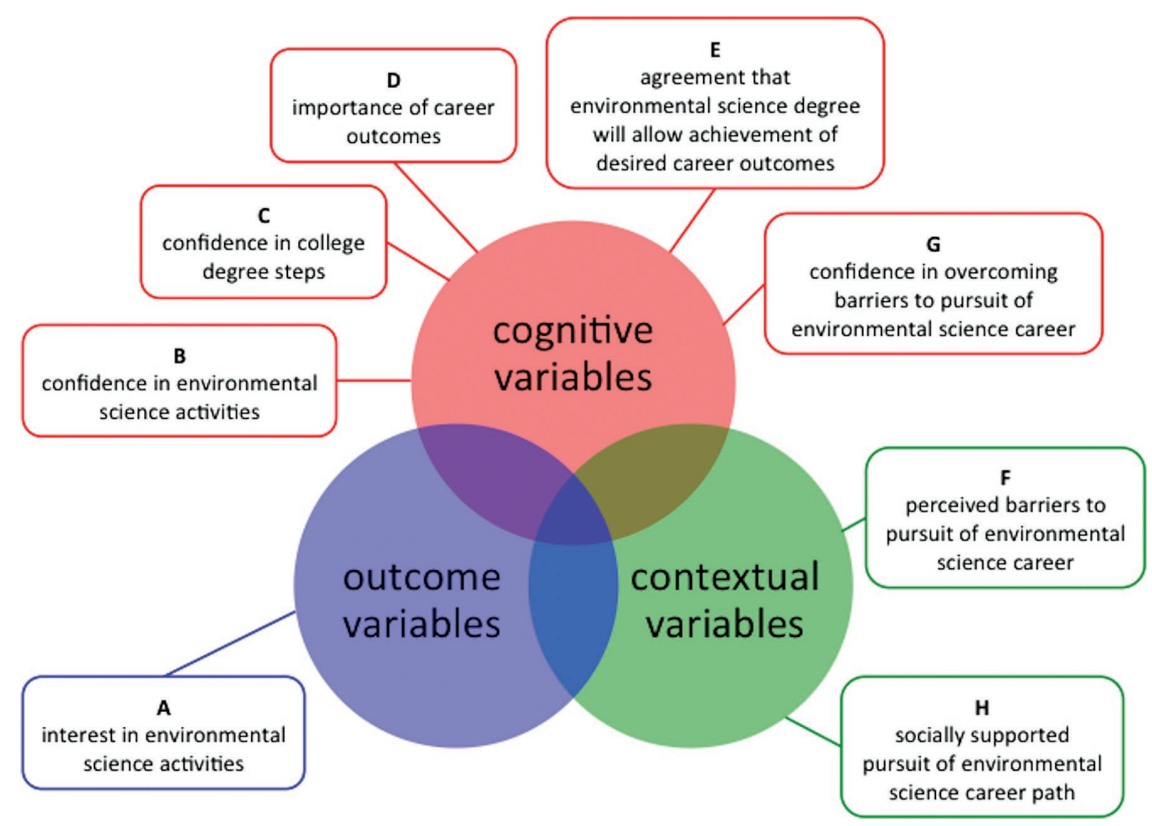

FIGURE 1. Connection of environmental science career interest survey sections to the three interrelating social cognitive career theory variable domains: cognitive (self-efficacy/confidence and outcome expectations), contextual (role model influence, social supports, and perceived barriers), and outcome (interest in environmental science).
Program Climate Surveys. Climate surveys were designed to assess the personal experience of the youth participants at regular points during SIFT (early-multiple mid-post) and TERF (multiple mid-post), and also within 1 to 3 years after participation in either program. The surveys consisted of five-point Likert-scaled level of agreement items and free response to open-ended questions that included reflection on their work with scientists. Responses to the open-ended survey questions were analyzed for emergent themes (described below). Some survey items varied according to the program context at a particular collection time point. The final alumni follow-up climate survey captured additional information on college majors, longer-term reflection on the benefits of having participated in SIFT and TERF, and whether additional research activities were pursued before and during college. This survey was administered 1 to 3 years after participation in SIFT as follows: cohort 1 in 2012 (3 years after participation in SIFT), cohort 2 in 2012-2013 
(2-3 years after participation in SIFT), cohort 3 in 2013 ( 2 years after participation in SIFT), and cohort 4 in 2013 (1 year after participation in SIFT). Data on college majors and additional research activities were also collected through alumni's personal communications with program staff that occurred via email and social media 4 to 6 years after participation in either program.

Participants' intended college majors were captured before starting SIFT, and their later intended or declared college majors were captured as described above. The various specified majors were grouped into the following categories: environmental STEM, other STEM, non-STEM, and undecided. The environmental STEM major category included any science, technology, engineering, or mathematics major that is field-oriented (e.g., environmental biology, zoology, environmental engineering, geosciences, archaeology, etc.). The resulting data were analyzed to determine whether actual majors were related to the completion of both programs (SIFT+TERF) and also to the previously intended majors. Categorical analysis was performed using PROC CATMOD in SAS 9.4.

Emergent Themes. During the analysis of the climate survey free-response text, repeated references to youth perceptions were grouped by commonalities. When these commonalities clustered, they were identified as emergent themes and subsequently organized into pattern codes. Regular presence during SIFT and TERF program activities gave an external evaluator the opportunity for observation and on-the-spot interviews. Observation and emergent themes informed the interview structure. Interview responses validated the accuracy of the themes while also providing more contextual understanding. Additional verification of theme accuracy was provided during discussion with mentoring scientists and program staff. This process informed continued program adjustment and provided new items for subsequent participant climate surveys. This cyclical process of theme verification by various stakeholders strengthens the validity of the pattern codes (Miles and Huberman, 1994). Our qualitative approach in this study was constructivist in nature, allowing for the competing and conflicting realities of multiple stakeholders and participants to show the whole picture (Lincoln, 1990).

\section{RESULTS}

\section{Factor Analysis of the Social Cognitive Career Variables}

We assessed the internal consistency and reliability of the environmental science career interest survey via principal components analysis of survey items at baseline. The following factors emerged: a three-factor solution for interest in environmental science activities (A1, A2, A3), a two-factor solution for confidence in completing environmental science activities (B1, B2), a one-factor solution for confidence in college degree steps (C1), a two-factor solution for career outcome importance (D1, D2), a one-factor solution for environmental science degree will allow achievement of desired career outcomes (E1), a three-factor solution for perceived barriers to pursuit of an environmental science career (F1, F2, F3), a one-factor solution for confidence in overcoming barriers to pursuit of an environmental science career (G1), and a three-factor solution for the perception of socially supported pursuit of an environmental science career path (H1, H2, H3).
The emergent factors are shown in Table 1 along with each factor's Cronbach's alpha.

\section{RM-ANOVAs Pre-, Mid-, and Post-SIFT}

Six of the 16 newly developed factors from the environmental science career interest survey demonstrated significant changes in youth responses over the course of SIFT (Table 2). There were statistically significant, albeit small, decreases over time in the mean scores for science practices interest factors A1 ( $p=$ $0.007)$ and $\mathrm{A} 2(p=0.003)$. Mean scores for science practices confidence factors B1 $(p=0.001)$ and B2 $(p=0.017)$ were reported highest at mid-SIFT and remained above baseline levels post-SIFT. Similarly, mean perceived financial barriers factor F3 scores $(p=0.006)$ were highest at mid-SIFT and approached baseline levels post-SIFT. Mean scores for career factor D2 $(p=0.002)$ were lowest post-SIFT.

\section{RM-ANOVAs Pre-, Mid-, and Post-SIFT for SIFT-Only versus Future-TERF}

Within our study, we had two different participant groups, those who completed only SIFT (SIFT-only) and those who went on to participate in TERF (future-TERF). Table 3 contains the mean factor scores across SIFT by participant group. RM-ANOVAs across the groups indicated six factors had significant change in mean scores over time for both groups. RM-ANOVAs between the groups indicated the magnitude of change in five factors differed significantly by group.

For general science indoor practices interest factor A1 ( $p=$ 0.013 ) and environmental science outdoor practices interest factor A2 ( $p=0.003)$, both groups showed significant decline in mean scores over time. There was also marginal significance between the two groups for factor A2 $(p=0.050)$, with futureTERF youth having less of a decline over time. While scores did not change significantly over time, future-TERF youth reported greater environmental science deep-thinking interest (factor A3) than SIFT-only program participants throughout SIFT ( $p=$ 0.006).

Significant changes over time were observed in indoor and outdoor scientific practices confidence factors B1 $(p=0.000)$ and B2 $(p=0.009)$. Both SIFT-only and future-TERF participants grew in confidence in their indoor and outdoor scientific practices after the first part of SIFT (training week). Additionally, the magnitude of change over time between the two groups in outdoor practices confidence level was significant (B2 $p=0.036$ ), with future-TERF youth reporting higher confidence.

Mean scores for employment basics factor D1 showed no significant change, but future-TERF youth reported a significantly lower importance overall throughout SIFT ( $p=0.015)$. Intangible career benefits factor D2 showed significant change in mean scores over time for both groups $(p=0.002)$, but future-TERF youth reported significantly lower importance overall than SIFT-only participants across all time points ( $p=$ 0.018).

Mean scores for the perceptions of external barriers to pursuit of an environmental science career factor F2 did not significantly change over time. However, future-TERF youth reported significantly lower barrier perception throughout SIFT in comparison with SIFT-only youth $(p=0.010)$. Perceptions of financial barriers to pursuit of an environmental science career factor F3 
TABLE 1. Emergent factors from principal components analysis and internal-consistency reliability (Cronbach's alpha) of items loading on each factor at baseline (pre SIFT, $N=207$ )

\begin{tabular}{|c|c|c|c|}
\hline Survey sections & Emergent factors & Survey items & Cronbach's alpha \\
\hline \multirow{3}{*}{$\begin{array}{l}\text { A. Level of interest in environmental science } \\
\text { activities }\end{array}$} & A1: Level of interest in general science indoor practices & $1-3,6$ & 0.74 \\
\hline & $\begin{array}{l}\text { A2: Level of interest in environmental science outdoor } \\
\text { practices }\end{array}$ & $4,9,10,11$ & 0.67 \\
\hline & $\begin{array}{l}\text { A3: Level of interest in deep thinking about environ- } \\
\text { mental science }\end{array}$ & 7,8 & 0.71 \\
\hline $\begin{array}{l}\text { B. Level of confidence in environmental } \\
\text { science activities }\end{array}$ & $\begin{array}{l}\text { B1: Level of confidence in general science indoor } \\
\text { practices }\end{array}$ & $1-4,6$ & 0.84 \\
\hline $\begin{array}{l}\text { C. Level of confidence in completion of college } \\
\text { science degree steps }\end{array}$ & $\begin{array}{l}\text { C1: Level of confidence in completion of college } \\
\text { science degree steps }\end{array}$ & $1-4$ & 0.90 \\
\hline \multirow[t]{2}{*}{ D. Level of importance of career outcomes } & D1: Level of importance of career or employment basics & $1-3,8$ & 0.72 \\
\hline & $\begin{array}{l}\text { D2: Level of importance of deeper meaning and } \\
\text { intangible career benefits }\end{array}$ & $4,7,9$ & 0.58 \\
\hline \multirow[t]{3}{*}{$\begin{array}{l}\text { F. Level of perceived barriers to pursuit of } \\
\text { environmental science career }\end{array}$} & $\begin{array}{l}\text { F1: Level of perceived personal/internal barriers to } \\
\text { pursuit of environmental science career }\end{array}$ & $1,5-7$ & 0.79 \\
\hline & $\begin{array}{l}\text { F2: Level of perceived external barriers to pursuit of } \\
\text { environmental science career }\end{array}$ & $2,9,10,16$ & 0.73 \\
\hline & $\begin{array}{l}\text { F3: Level of perceived financial barriers to pursuit of } \\
\text { environmental science career }\end{array}$ & 11,13 & 0.62 \\
\hline $\begin{array}{l}\text { G. Level of confidence in overcoming barriers } \\
\text { to pursuit of environmental science career }\end{array}$ & $\begin{array}{l}\text { G1: Confidence in overcoming perceived barriers to } \\
\text { pursuit of environmental science career }\end{array}$ & $1-16$ (all) & 0.97 \\
\hline $\begin{array}{l}\text { H. Level of agreement that pursuit of } \\
\text { environmental science career path will have } \\
\text { role model influence and social support }\end{array}$ & $\begin{array}{l}\text { H1: Level of agreement that pursuit of environmental } \\
\text { science career path will be supported by others }\end{array}$ & $8-10$ & 0.84 \\
\hline
\end{tabular}

showed significant change in mean scores over time for both groups, with highest perception of barriers reported at mid-SIFT $(p=0.010)$.

\section{RM-ANOVAs Pre-, Mid-, Post-SIFT, and Post-TERF}

For those youth who continued on in their environmental career exploration by completing TERF (SIFT+TERF), the results of their environmental science career interest survey at a final postprogram time point are presented in Table 4. Five factors demonstrated significant change in mean scores over time. Mean scores for interest in indoor and outdoor science practices factors A1 $(p=0.005)$ and A2 $(p=0.016)$ significantly decreased over time. Mean scores on perceived financial barriers (factor F3, $p=0.004$ ) showed significant change over time, with the highest mean score at mid-SIFT and a drop to below the pre-SIFT level after the TERF apprenticeship experience. Over time, TERF participants reported increasingly higher levels of agreement that pursuit of an environmental science career would include a mentor and peers with similar interests (factor H2, $p=0.005$ ) and an inspirational model (factor H3, $p<0.001)$.

\section{Climate Surveys}

Education and Career-Oriented Benefits. Cohorts 1-4 were asked to reflect back on their experiences in SIFT and TERF and to rank a list of nine possible benefits 1 to 3 years after program completion. If one of the listed items was not a perceived benefit, they were instructed to select N/A. The benefits ranked in importance as first, second, or third were analyzed in aggregate. Responses of those who completed both SIFT and TERF were separated out for comparison with those who only completed SIFT (Figure 2). For both groups, gaining knowledge of environmental field research was ranked as a top three benefit. However, the groups placed differing values on other program benefits. SIFT+TERF youth identified higher value in the more career-oriented impacts (career and education ideas, career and education contacts, mentors, role models). SIFT-only participants placed higher value on some less career-oriented benefits (knowledge about personal capabilities and interests, new friends, summer income).

College Major Choices. We identified 95 youth participants' intended college majors before their SIFT participation (during 
TABLE 2. RM-ANOVAs testing the significance of change in mean environmental science career interest factor scores before, during, and after SIFT for all youth participants who completed SIFT $(N=121)^{\text {a }}$

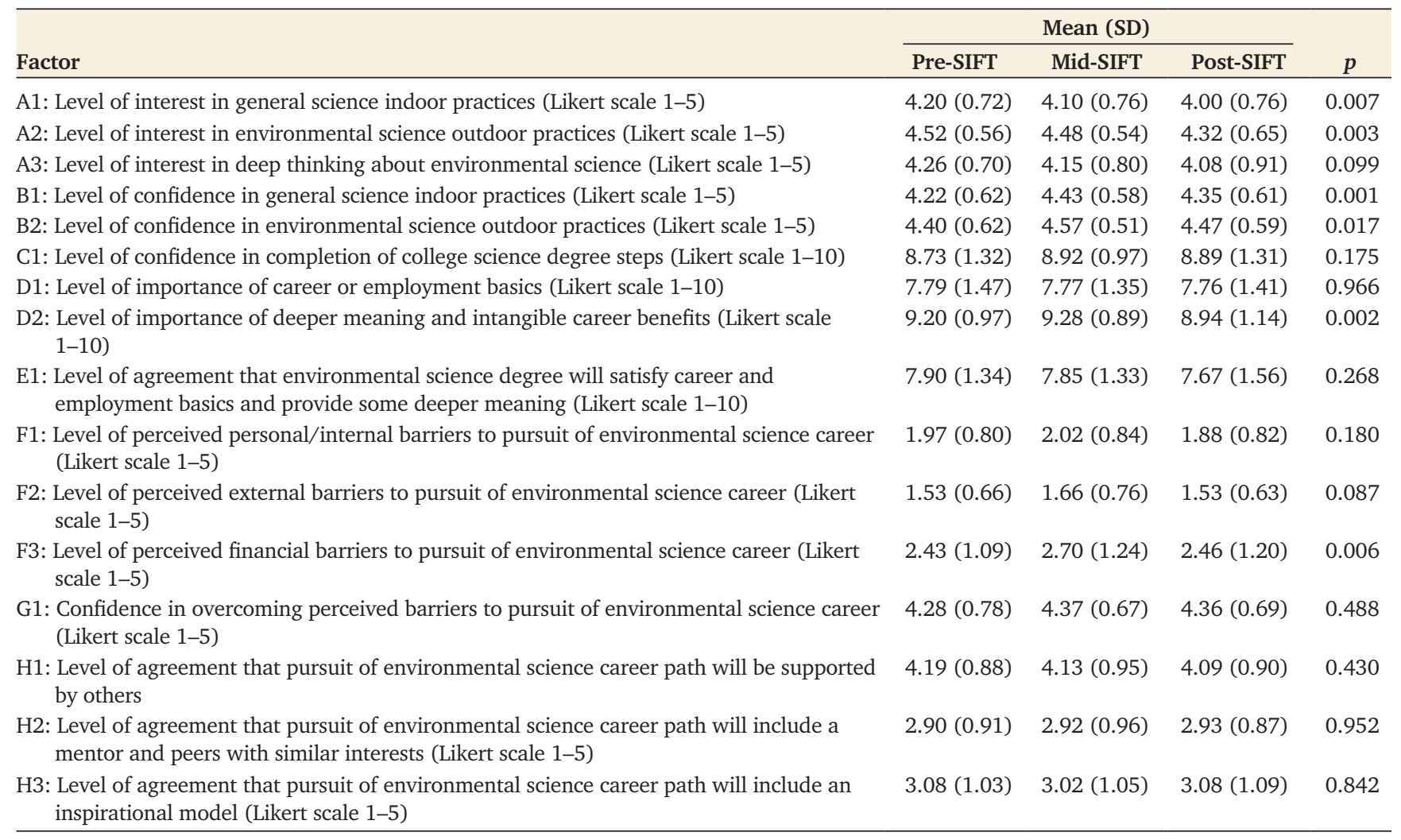

aTwo-tailed $p$ values $<0.05$ were considered statistically significant.

10th or 11th grade of high school) and their later intended or declared majors once they were enrolled in college or had completed an undergraduate degree. As shown in Figure 3, some participants in both the SIFT-only and SIFT+TERF groups changed their minds about their college majors from before SIFT to during college, and as expected, the number of undecided youth decreased for both groups. For the 90 participants who indicated interest in an environmental STEM major or another STEM major or were undecided on a college major before starting SIFT, categorical analysis revealed that completion of TERF $\left(\chi^{2}=12.18, d f=2, p=0.002\right)$ and pre-SIFT intended major $\left(\chi^{2}=18.14, d f=4, p=0.001\right)$ were significant predictors of actual major later on. Table 5 presents comparison of SIFT-only participants with SIFT+TERF participants. For those who indicated an intended environmental STEM major, the likelihood of actually majoring in environmental STEM was similar for both groups (probability 0.600 SIFTonly, probability 0.667 SIFT+TERF). However, there were large differences between the SIFT-only and SIFT+TERF groups for the other two intended major categories. When indicating initial interest in other STEM majors, SIFT-only youth were very unlikely to end up as environmental STEM majors (probability 0), whereas SIFT+TERF youth had a good chance of switching to environmental STEM (probability 0.417). For those who were undecided on a college major before starting SIFT, those who only completed SIFT had a somewhat distributed probability of majoring in the three categories (environmental STEM probability 0.273, other STEM probability 0.455 , non-STEM probability 0.273 ). In contrast, those undecided youth who completed both SIFT and TERF had very high likelihood of going on to major in environmental STEM (probability 0.800), no likelihood of majoring in another STEM field (probability 0), and some likelihood of majoring in a non-STEM field (probability 0.200).

Engagement in Additional Research Activities before and during College. We asked 170 SIFT and TERF alumni to report back on whether they had participated in additional research activities during the end of high school and into college. We received 36 affirmative responses. We determined 28 alumni had one or more additional precollege research experiences and, of those, 12 returned to the field station for an additional TERF session. We determined that 35 had one or more early college research experiences. A subset of 14 were former SIFT-only participants, a subset of 21 were former TERF participants, and a subset of 11 returned to the field station as undergraduate fellows.

\section{Emergent Themes}

We identified 14 emergent themes from climate survey free responses (Table 6) and organized them into the following four categorical pattern codes: reality of scientific fieldwork (five themes), self-knowledge gain (three themes), view of bigger picture (three themes), and relationships with professionals (three themes). In the Discussion section, some significant quantitative results are interpreted with contextual 
TABLE 3. RM-ANOVAs testing the significance of differences in mean environmental science career interest factor scores before, during, and after SIFT, grouping by SIFT-only $(n=58)$ vs. future-TERF youth $(n=60)$ participants ${ }^{a}$

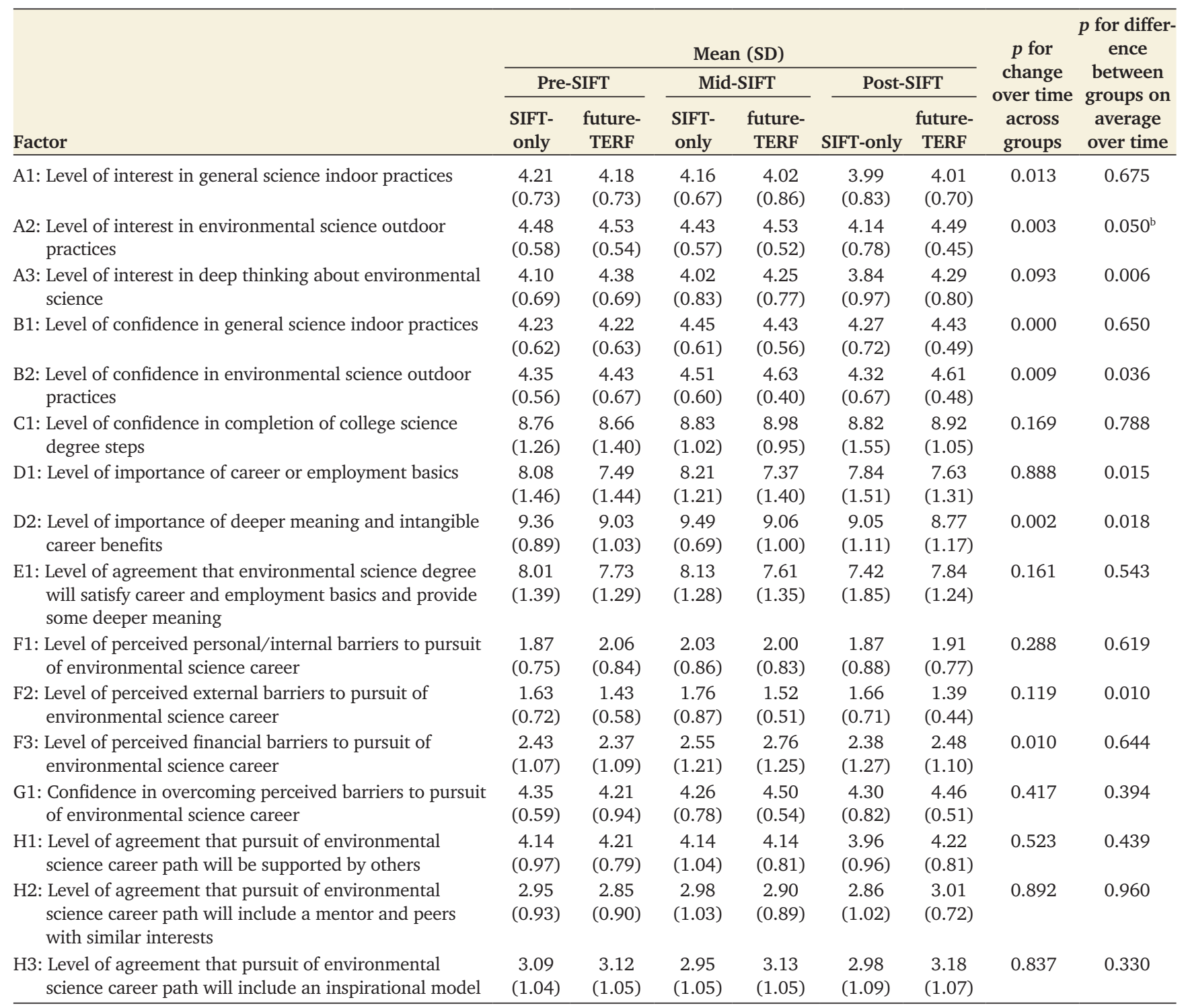

${ }^{a}$ Two-tailed $p$ values $<0.05$ were considered statistically significant.

${ }^{\mathrm{b}}$ Marginal significance.

information from the pattern codes and themes, and sample quotes are provided as thematic examples. In other cases, quantitative results are unable to be contextualized, because related supporting themes did not emerge from within the climate survey responses.

\section{DISCUSSION}

This paper describes the participant impacts during a two-stage apprenticeship model of field research experiences for precollege youth interested in environmental sciences. The model is designed to encourage entry into the environmental field research career pathway and our long-term study of the participants was designed to examine the extent to which the model achieves that goal. SIFT is an introductory field-skills training program, and TERF is a more advanced field research internship program. The consecutive programs are independent from formal schooling and take place at a nature reserve and university field station. Both include the opportunity to assist career scientists one-on-one with in-progress research projects.

\section{Participation in SIFT Changed Youth Thinking about Environmental Science Career Paths}

As SIFT was specifically designed for exploration of environmental biology field research activities, it was hoped that participation would clarify youth thinking about an environmental science career path. Our research suggests SIFT participants gained a more realistic view of what environmental science is like, including new awareness of how monotonous certain aspects of fieldwork can be. They also experienced increased confidence in environmental science activities and a shift in the degree to which they felt financial barriers impeded them from pursuing a career in environmental science. 
TABLE 4. RM-ANOVAs testing the significance of change in mean environmental science career interest factor scores from pre-SIFT to post-TERF for youth participants who completed both SIFT and TERF $(n=51)^{\mathrm{a}}$

\begin{tabular}{|c|c|c|c|c|c|}
\hline \multirow[b]{2}{*}{ Factor } & \multicolumn{4}{|c|}{ Mean (SD) } & \multirow[b]{2}{*}{$p$} \\
\hline & Pre-SIFT & Mid-SIFT & Post-SIFT & Post-TERF & \\
\hline A1: Level of interest in general science indoor practices & $\begin{array}{c}4.25 \\
(0.69)\end{array}$ & $\begin{array}{c}4.08 \\
(0.79)\end{array}$ & $\begin{array}{c}4.05 \\
(0.69)\end{array}$ & $\begin{array}{c}3.93 \\
(0.84)\end{array}$ & 0.005 \\
\hline A2: Level of interest in environmental science outdoor practices & $\begin{array}{c}4.62 \\
(0.46)\end{array}$ & $\begin{array}{c}4.51 \\
(0.54)\end{array}$ & $\begin{array}{c}4.50 \\
(0.45)\end{array}$ & $\begin{array}{c}4.35 \\
(0.62)\end{array}$ & 0.016 \\
\hline A3: Level of interest in deep thinking about environmental science & $\begin{array}{c}4.48 \\
(0.57)\end{array}$ & $\begin{array}{c}4.34 \\
(0.75)\end{array}$ & $\begin{array}{c}4.34 \\
(0.76)\end{array}$ & $\begin{array}{c}4.35 \\
(0.75)\end{array}$ & 0.268 \\
\hline B1: Level of confidence in general science indoor practices & $\begin{array}{c}4.27 \\
(0.58)\end{array}$ & $\begin{array}{c}4.40 \\
(0.56)\end{array}$ & $\begin{array}{c}4.43 \\
(0.44)\end{array}$ & $\begin{array}{c}4.49 \\
(0.54)\end{array}$ & 0.073 \\
\hline B2: Level of confidence in environmental science outdoor practices & $\begin{array}{c}4.50 \\
(0.64)\end{array}$ & $\begin{array}{c}4.61 \\
(0.42)\end{array}$ & $\begin{array}{c}4.61 \\
(0.49)\end{array}$ & $\begin{array}{c}4.65 \\
(0.51)\end{array}$ & 0.583 \\
\hline C1: Level of confidence in completion of college science degree steps & $\begin{array}{c}8.81 \\
(1.22)\end{array}$ & $\begin{array}{c}8.98 \\
(0.94)\end{array}$ & $\begin{array}{c}9.00 \\
(1.05)\end{array}$ & $\begin{array}{c}9.10 \\
(0.99)\end{array}$ & 0.462 \\
\hline D1: Level of importance of career or employment basics & $\begin{array}{c}7.55 \\
(1.34)\end{array}$ & $\begin{array}{c}7.36 \\
(1.36)\end{array}$ & $\begin{array}{c}7.65 \\
(1.22)\end{array}$ & $\begin{array}{c}7.88 \\
(1.28)\end{array}$ & 0.150 \\
\hline D2: Level of importance of deeper meaning and intangible career benefits & $\begin{array}{c}9.07 \\
(1.04)\end{array}$ & $\begin{array}{c}9.08 \\
(1.08)\end{array}$ & $\begin{array}{c}8.79 \\
(1.22)\end{array}$ & $\begin{array}{c}8.93 \\
(0.97)\end{array}$ & 0.143 \\
\hline $\begin{array}{l}\text { E1: Level of agreement that environmental science degree will satisfy career and } \\
\text { employment basics and provide some deeper meaning }\end{array}$ & $\begin{array}{c}7.84 \\
(1.27)\end{array}$ & $\begin{array}{c}7.76 \\
(1.30)\end{array}$ & $\begin{array}{c}7.97 \\
(1.28)\end{array}$ & $\begin{array}{c}7.90 \\
(1.35)\end{array}$ & 0.582 \\
\hline $\begin{array}{l}\text { F1: Level of perceived personal/internal barriers to pursuit of environmental science } \\
\text { career }\end{array}$ & $\begin{array}{l}2.08 \\
(0.75)\end{array}$ & $\begin{array}{c}2.01 \\
(0.82)\end{array}$ & $\begin{array}{c}1.91 \\
(0.81)\end{array}$ & $\begin{array}{c}1.79 \\
(0.73)\end{array}$ & 0.068 \\
\hline F2: Level of perceived external barriers to pursuit of environmental science career & $\begin{array}{c}1.41 \\
(0.38)\end{array}$ & $\begin{array}{c}1.51 \\
(0.48)\end{array}$ & $\begin{array}{c}1.42 \\
(0.51)\end{array}$ & $\begin{array}{c}1.38 \\
(0.50)\end{array}$ & 0.167 \\
\hline F3: Level of perceived financial barriers to pursuit of environmental science career & $\begin{array}{c}2.35 \\
(1.16)\end{array}$ & $\begin{array}{c}2.66 \\
(1.21)\end{array}$ & $\begin{array}{c}2.39 \\
(1.11)\end{array}$ & $\begin{array}{c}2.15 \\
(1.01)\end{array}$ & 0.004 \\
\hline $\begin{array}{l}\text { G1: Confidence in overcoming perceived barriers to pursuit of environmental science } \\
\text { career }\end{array}$ & $\begin{array}{c}4.16 \\
(0.96)\end{array}$ & $\begin{array}{c}4.46 \\
(0.57)\end{array}$ & $\begin{array}{c}4.44 \\
(0.54)\end{array}$ & $\begin{array}{c}4.44 \\
(0.70)\end{array}$ & 0.269 \\
\hline $\begin{array}{l}\text { H1: Level of agreement that pursuit of environmental science career path will be } \\
\text { supported by others }\end{array}$ & $\begin{array}{c}4.27 \\
(0.79)\end{array}$ & $\begin{array}{l}4.17 \\
(0.85)\end{array}$ & $\begin{array}{c}4.32 \\
(0.76)\end{array}$ & $\begin{array}{l}4.40 \\
(0.73)\end{array}$ & 0.230 \\
\hline $\begin{array}{l}\text { H2: Level of agreement that pursuit of environmental science career path will } \\
\text { include a mentor and peers with similar interests }\end{array}$ & $\begin{array}{l}2.85 \\
(0.86)\end{array}$ & $\begin{array}{c}2.82 \\
(0.89)\end{array}$ & $\begin{array}{l}2.96 \\
(0.74)\end{array}$ & $\begin{array}{c}3.40 \\
(0.95)\end{array}$ & 0.005 \\
\hline $\begin{array}{l}\text { H3: Level of agreement that pursuit of environmental science career path will } \\
\text { include an inspirational model }\end{array}$ & $\begin{array}{l}2.98 \\
(1.05)\end{array}$ & $\begin{array}{c}3.11 \\
(1.09)\end{array}$ & $\begin{array}{c}3.24 \\
(1.11)\end{array}$ & $\begin{array}{c}3.86 \\
(1.12)\end{array}$ & $<0.001$ \\
\hline
\end{tabular}

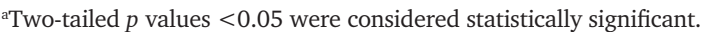

The small decrease in mean scores for environmental science activities interest factors A1 (e.g., interest in learning use of scientific instruments/tools, writing up experimental results, doing research in a lab) and A2 (e.g., interest in performing experiments, hiking/camping in wilderness, collaborating on environmental or ecological research, collecting samples in nature) is likely due to SIFT providing clarification on the reality of environmental science research activities and thought processes. Through their experiences in SIFT, participants were trained in and then applied basic field skills. This was followed by brief experiences with scientists using these skills on actual research. Youth with initially high levels of interest found out what environmental science research is like in the real world, and, consequently, their interest changed (pattern code: reality of scientific fieldwork). However, it is important to point out that these mean interest scores started high and were still quite high at the end of SIFT. The realities provided by participation in SIFT may have influenced their level of interest but in no way caused youth to abandon their interest in environmental science activities. Rather, it may have somewhat tempered their interest in pursuing a career in an environmental field science (pattern code: self-knowledge gain).
"While observing insects, I found that although I very much enjoy working outside, I am not an exceptionally patient person, so field research may not be the best fit for me." (SIFT cohort 2, climate survey)

"I realize that field work isn't easy it's actually pretty difficult and the weather can be harsh so perhaps field work isn't for me." (SIFT cohort 2, climate survey)

"The animal behavior project was encouraging, since I enjoy working with animals much more than plants. It's really more what I learn about the implications of the research, and it's results that interest me. Sorting insects is not the most exciting thing in the world, but the data you collect is very interesting and important." (SIFT cohort 4, research project reflection)

We suspect the slight overall decrease in career meaning factor D2 (e.g., having satisfying or exciting work that makes a difference) may have to do with maturing awareness of the realities of work and whether deeper meaning can be found in monotonous research tasks (emergent theme: monotony). Some participants found the monotony 


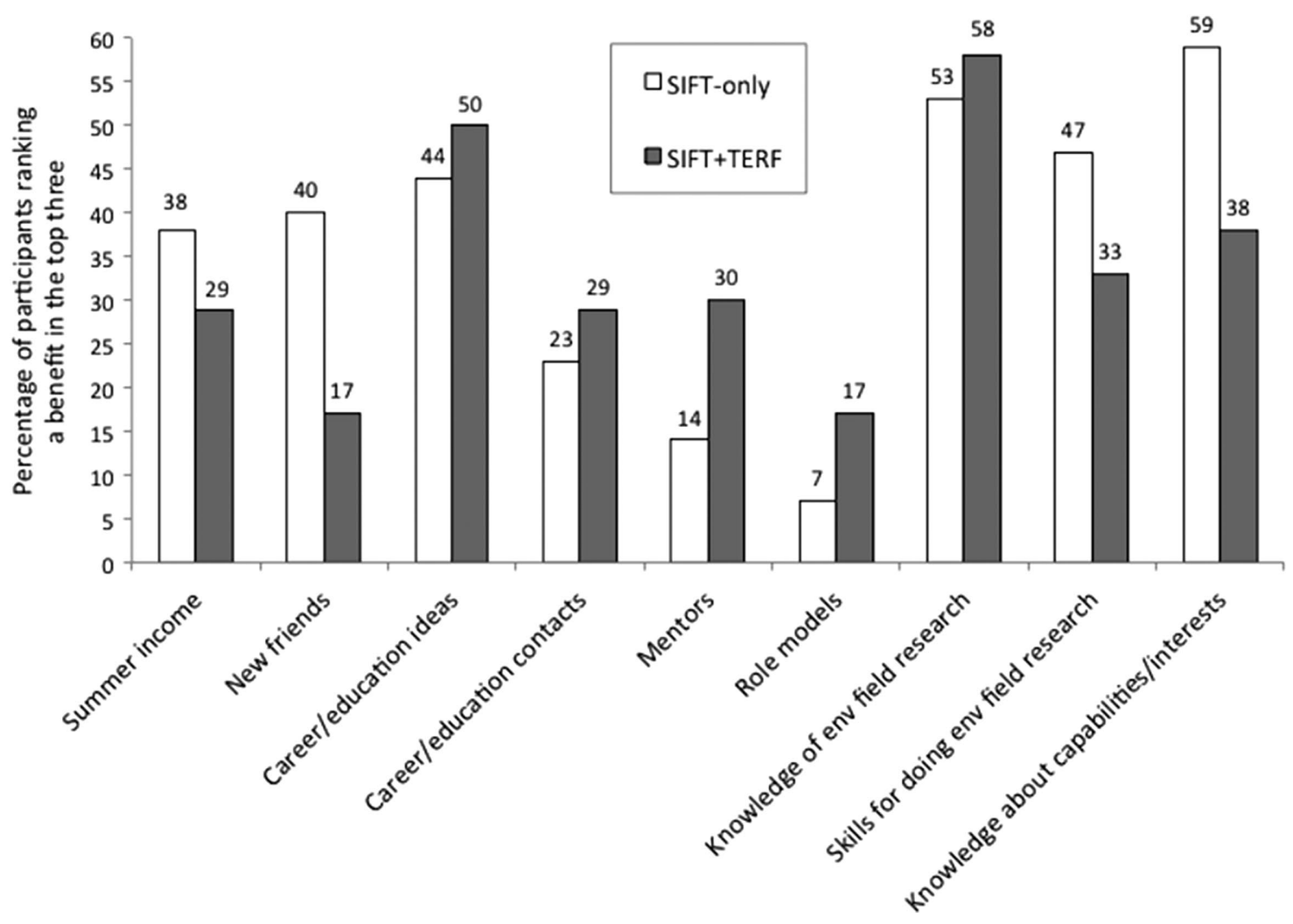

FIGURE 2. Percentage of participants ranking a benefit in the top three when reflecting back upon their participation ( $N=42 ; \mathrm{SIFT}$-only $n=17$; SIFT+TERF $n=25$ ). Alumni follow-up climate survey item: "What did you gain by putting time into SIFT or TERF activities? Rank any of the following benefits that you found in your participation in SIFT and/or TERF. Give a 1 to the most important item and so forth through the nine items. If an item was not a benefit for you check the N/A box instead of giving it a ranking number."

discouraging to further exploration of an environmental research career, while others did not. This could be related to the projects they were engaged in and whether they had long enough time to find any personal meaning in the work that would overcome the tedious aspects (pattern code: view of bigger picture; emergent themes: research importance, making a difference).

"I initially thought that bug collecting would be a monotonous job, and linear, and to a minimum it was. But I found that sifting through dirt can be quite engaging as it gives you time to analyze what's in front of you." (SIFT cohort 3, research project reflection)

"I learned that the monotonous work is not the most fun, but it's not anything that would make me lean away from a career in environmental field research." (SIFT cohort 4, research project reflection)

"I asked him [field research scientist] multiple questions on the different specimen we saw. He was a joy to work with because he really understood the project and was grateful for our time. He also helped me understand that some work in field research may be monotonous, but it is often new and exciting, too. It is all part of the job." (SIFT cohort 4, research project reflection)
Confidence in environmental science activities started out high for general science indoor practices factor B1 (e.g., confidence in learning use of scientific instruments/tools, writing up experimental results, performing experiments, doing research in a lab) and environmental science outdoor practices factor B2 (e.g., confidence in doing research in the field, hiking/camping in wilderness, collaborating on environmental or ecological research, collecting samples in nature). Both factors went up and then down over the course of SIFT, but as they landed higher than at baseline, there was an overall slight increase in confidence. The already high confidence level was somewhat strengthened by participation in SIFT. Confidence went up as a result of field-training activities, but then working with scientists tested the application of new skills (pattern code: self-knowledge gain; emergent themes: capacity for this work, commitment to this type of work).

"I learned that I am very observant of nature and enjoy being outdoors. I am not bothered by being outside because I have realized that there is a delicate world that many people are unaware of." (SIFT cohort 4, research project reflection)

"Before SIFT I knew I was interested in natural science, but the whole experience truly confirmed for me that I want to work with the environment. I felt much more confident after SIFT in 


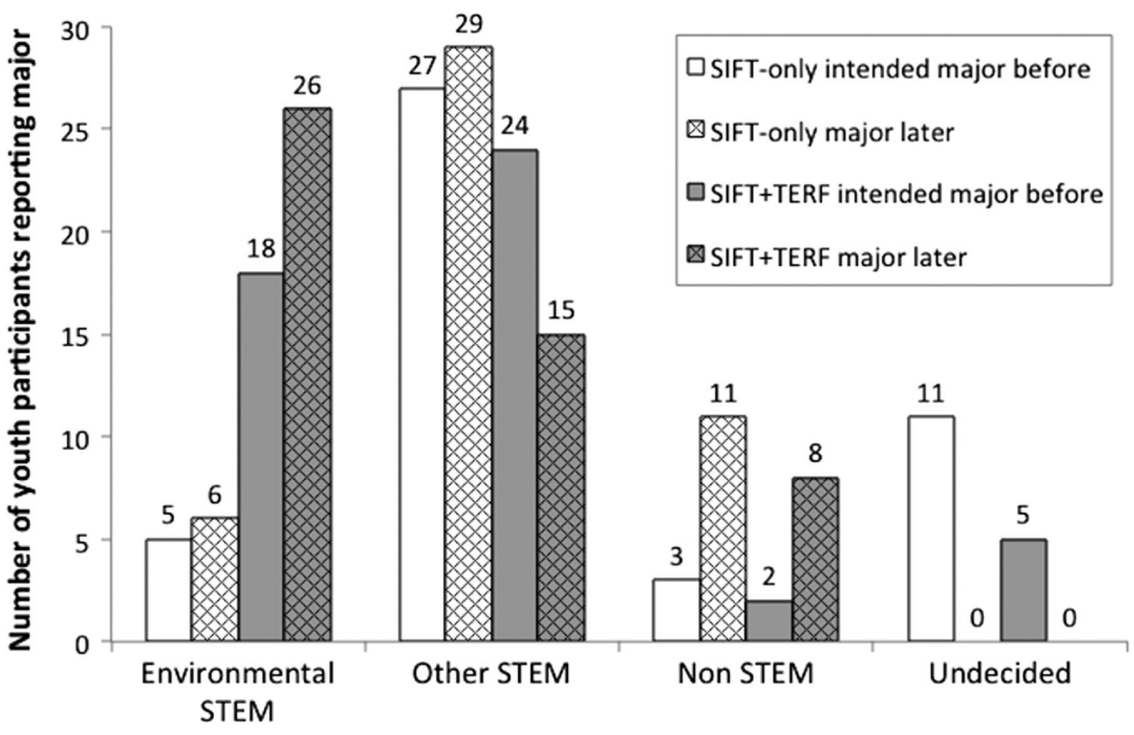

FIGURE 3. Intended college major choices of participant youth before their participation in SIFT compared with their intended or declared major later during college enrollment ( $N=$ 95; SIFT-only $n=46$; SIFT+TERF $n=49$ ).

my abilities to collect data and observe. It helped me truly understand how scientists research outdoors." (SIFT cohort 4, alumni follow-up climate survey)

Pre-SIFT, youth agreed they were somewhat likely to encounter certain financial barriers to pursuit of an environmental science career (factor F3, e.g., having to work while going to school, no financial support). This agreement increased

TABLE 5. Categorical analysis (using PROC CATMOD) of the effect of TERF program completion (SIFT-only vs. SIFT+TERF) and pre-SIFT intended college major on actual college major $(N=90)$

\begin{tabular}{lclll}
\hline \multirow{2}{*}{$\begin{array}{l}\text { Program } \\
\text { completion }\end{array}$} & & & \multicolumn{2}{c}{ Observed } \\
\cline { 4 - 5 } PIFT-only & Env STEM & Env STEM & 0.600 & 0.219 \\
& $(n=5)$ & Other STEM & 0 & 0 \\
& & Non-STEM & 0.400 & 0.219 \\
& Other STEM & Env STEM & 0 & 0 \\
& $(n=27)$ & Other STEM & 0.889 & 0.061 \\
& & Non-STEM & 0.111 & 0.061 \\
SIFT+TERF & Env STEM & Env STEM & 0.667 & 0.111 \\
& $(n=18)$ & Other STEM & 0.167 & 0.088 \\
& & Env STEM & 0.273 & 0.134 \\
& & Other STEM & 0.455 & 0.150 \\
& & Non-STEM & 0.167 & 0.088 \\
& Other STEM & Env STEM & 0.417 & 0.101 \\
& $(n=24)$ & Other STEM & 0.500 & 0.102 \\
& & Non-STEM & 0.083 & 0.056 \\
& Undecided & Env STEM & 0.800 & 0.179 \\
& $(n=5)$ & Other STEM & 0 & 0 \\
& & Non STEM & 0.200 & 0.179 \\
\hline
\end{tabular}

Env STEM, environmental STEM major. midprogram and then decreased postprogram, but to a level higher than at baseline. As the youth got closer in time to college plans and more realistic assessment of college costs, it is possible that additional barriers and solutions were being processed, and this is what we were seeing as the scores for this factor changed. This is supported by discussions participants had with scientists at all levels (undergraduates, technicians, postdoctoral scientists, faculty), by inquiries from parents, and by requests to program staff and scientists for recommendation letters for colleges and scholarships. However, without comparison with a control group it is unclear whether a shift in perception of financial barriers is common to high school students at this time in their educational progression.

When evaluating science enrichment program impacts, pre-post survey scores may not be sufficient to detect how a program influenced change, especially when youth who have chosen to participate in the program may already have high interest (Stake and Mares, 2001). While SIFT participation was not associated with a significant change in participants' perceptions of 10 factors, it is important to note where their mean scores actually fell. Over three time points, these youth as a group had a high level of interest in deep thinking about environmental science (A3 $\bar{x}=4.16$ on a five-point scale), a high level of confidence in completing science degree steps ( $\mathrm{C} 1 \bar{x}=8.85$ on a 10-point scale), some agreement that that an environmental science degree would satisfy career and employment basics and provide some deeper meaning (E1 $\bar{x}=7.81$ on a 10-point scale), a low level of perceived personal/internal barriers to pursuit of an environmental science career (F1 $\bar{x}=1.96$ on a five-point scale), a low level of perceived external barriers to pursuit of an environmental science career (F2 $\bar{x}=1.57$ on a five-point scale), high confidence in overcoming perceived barriers to pursuit of an environmental science career (G1 $\bar{x}=4.34$ on a fivepoint scale), and agreement that their pursuit of an environmental science career path would be supported by others (H1 $\bar{x}=4.14$ on a five-point scale). Lack of significant movement in these factors might be rationalized as change in perception was not necessary because mean scores were already in a positive place. In contrast, the SIFT participants were somewhat neutral in their agreement that pursuit of an environmental science career path would include a mentor and peers with similar interests ( $\mathrm{H} 2 \bar{x}=2.92$ on a five-point scale) and that pursuit of an environmental science career path would include an inspirational model ( $\mathrm{H} 3 \bar{x}=3.06$ on a five-point scale). It is possible that their intermittent and limited interactions with scientists during SIFT were not enough to change their thinking about these factors. It should be noted that, while mean scores for these 10 factors did not change significantly, this does not mean that there were not individuals within the group who experienced changes in perception for these factors. 
TABLE 6. Pattern codes and emergent themes in the participant experience from climate survey free responses

\begin{tabular}{lcl}
\hline Pattern code & $\begin{array}{c}\text { Emergent } \\
\text { themes }\end{array}$ & Representative quotes \\
\hline Reality of & Monotony & Sometimes things get boring if you are doing them over and over again and I think I found it a little difficult
\end{tabular}

Reality of Monotony Sometimes things get boring if you are doing them over and over again and I think I found it a little difficult

scientific

fieldwork

Comfort with

outdoor

work

to get excited each time. (SIFT cohort 2, research project reflection)

I learned that there is lots of monotonous work, but they can make it fun. (SIFT cohort 4, research project reflection)

Some work can be monotonous, but it pays off and it can always be enjoyable in some way. (SIFT cohort 4, research project reflection)

I really enjoy being outside to do my work, regardless of what I am doing. (SIFT cohort 3, research project reflection)

I learned that I can tolerate the heat if I am engaged in an activity that is exciting to me. (SIFT cohort 3, research project reflection)

I don't like to collect data when its really hot. (SIFT cohort 3, research project reflection)

Participation in I found that the act of discovery, finding the insect I'm looking for or getting closer to the quota I'm trying to discovery reach, keeps me interested and pushes me toward a career in environmental science. (SIFT cohort 4, research project reflection)

Yes, because while it was a bit tedious at some points, when a discovery of something unknown, or just something different from the normal tree piece comes along it is completely exciting! (SIFT cohort 2, research project reflection)

Collaboration I enjoyed working around aquatics and working with a team of individuals, which made the work more fulfilling. (SIFT cohort 3, research project reflection)

I learned that it is nice to be able to work with someone on a project, which I think is important for field research. (SIFT cohort 3, research project reflection)

He [field research scientist] told us the necessity of having people of the same study somewhat close to you. If they are close to you, you can meet up with them and discuss your research with them. (SIFT cohort 4, research project reflection)

Many of the seminars helped me realize how tenacious, driven, and ambitious scientists are, since they spend years of their lives conducting huge and important studies over vast areas of space and time, usually in collaboration with many other scientists. (TERF cohort 2, climate survey)

Responsibility We learned about the importance of collecting data over seasons and we learned about tagging or identifying for detail specific plants for other scientists. They made me realize the importance of good notes and directions. (SIFT cohort 3, climate survey)

I mentioned for that for this project it was important to pay attention to details and to learn which details were important to pay attention in order to be able to sort and classify. This would be the same for other projects where you would need to be classifying species of plants or animals. I learned from this project how important it is to be aware of what you are doing so that you don't lose or spill any of the matter because this could affect the findings of the research. (SIFT cohort 2, research project reflection)

Self-knowledge Capacity for gain this work

I can certainly stand the work, which would lead me toward it, and I'm actually enjoying working out here. I wasn't expecting to like it this much. (TERF cohort 3, climate survey)

I learned that I get extremely tired of monotonous work that does not heavily engage my mind. I am under the impression that a career in environmental field research could contain a good deal of this type of work and might therefore not be the most ideal career path for me. (SIFT cohort 3, research project reflection)

Each week has required me to be open to learn new things, be hard working, focused and thorough in my approach. As for what I might be identifying in myself, I might say versatility, patience, resilience, and focus-along with simply enjoying working with other people-has given me a very positive feeling about field biology. (TERF cohort 3, TERF climate survey)

My TERF mentor gave me a great deal of responsibility, which showed me that I can handle stressful, monotonous, or challenging situations in any direction I choose to pursue. (TERF cohort 1, alumni follow-up climate survey)

Interest in this I learned the proper way to fish and bait a hook and the various species of fish that live all over the world. work This just added to my enthusiasm about becoming a zoologist! (SIFT cohort 3, research project reflection)

From this experience I was able to identify the aspects of research I enjoyed and did not enjoy. Overall, I think that being an environmental researcher may not be the best career for me, so instead I am considering fields such as environmental engineering which more so involve application of science rather than research. (TERF cohort 2, TERF climate survey)

The animal behavior project was encouraging, since I enjoy working with animals much more than plants. It's really more what I learn about the implications of the research, and it's [sic] results that interest me. Sorting insects is not the most exciting thing in the world, but the data you collect is very interesting and important. (SIFT cohort 4, research project reflection)

Commitment to I've learned that field research is really hard work, and you have to be dedicated to your task to really have this type of any fun. (SIFT cohort 2, research project reflection)

work After TERF I was pretty confident in my ability to do field research. Now I am confident that I want to pursue a career in some type of field research. (TERF cohort 2, alumni follow-up climate survey) 
TABLE 6. Continued

\begin{tabular}{lll}
\hline Pattern code & $\begin{array}{c}\text { Emergent } \\
\text { themes }\end{array}$ & Representative quotes \\
\hline & TERF helped me realize how passionate I am about the environment. It helped me realize that although I love
\end{tabular}

TERF helped me realize how passionate I am about the environment. It helped me realize that although I love field research, it may not be what's right for me for a career. However, it did help me realize I still want to stay involved in similar activities like Stream Team and other opportunities. TERF ultimately led me to the decision to persue environmental engineering so I can further my interests in water quality. (TERF cohort 1, alumni follow-up climate survey)

View of bigger picture Relationships Informs career
with
professionals
Career pathway Before going into SIFT I was unsure about what I wanted to study in college but after going through SIFT it showed me that I had more options than I thought I had. (TERF cohort 1, alumni follow-up climate survey)

My plans currently are to continue studying science and to conduct research, which I feel were greatly impacted by participating in SIFT. By completing this program, I discovered that I enjoy scientific work and would like to pursue a career in a related field. To that end, SIFT also increased my awareness of the different career paths, that one can take in the sciences. (SIFT cohort 3, alumni follow-up climate survey)

Before SIFT and TERF I had no clue what you could do in the science field. SIFT and TERF gave me a inside look on what I could do if I chose to go into something like Ecology. (TERF cohort 1, alumni follow-up survey)

Research I have learned that field research, although sometimes underrepresented, is important to many aspects of life importance such as the resources we use and also the environment we belong in. (TERF cohort 3, climate survey)

[The field scientist] helped us to understand the long-term implications of the project and how it could end up making a difference in how prairies are maintained. This shows the practical application of field research. (SIFT cohort 4, research project reflection)

This monotonous work of sorting and weighing plants seems slightly boring but knowing that this project is a global one makes it exciting to do this type of work. (SIFT cohort 4, research project reflection)

Making a differ- I loved being able to realize that when I get up in the morning and want to participate and learn from my ence $\quad$ experiences with TERF that this is what I should be doing. I should be doing something that I love to do and something that will make a difference in the world. (TERF cohort 2, climate survey)

Field research lends variety and the opportunity to expand, learn, and use creativity while working toward a common goal. Most of all, whether finding an answer to a complex question or, gaining new knowledge, advancement for humanity excites me the most. (SIFT cohort 3, research project reflection)

They (SIFT and TERF) were positive reinforcement that I have the ability to work with the environment and make a difference. It gave the idea of a career specifically geared for improving the environment is realistic and not unrealistic idea that I used to have. (TERF cohort 3, alumni follow-up climate survey)

I really enjoyed talking with the scientists on Thursday [scientist discussions on SIFT overnight]. They gave me a lot of tips about schooling and making choices in the field and also what they did. (SIFT cohort 4, climate survey)

He [field research scientist] basically told us his life story, how he got interested in it and how he became a scientist. (SIFT cohort 4, research project reflection)

My role model is all the researchers I've worked with during the time I have participated in the SIFT program because they gave me the experience of researching and doing what real scientists do and gave me a new idea of what I want to choose as a career. (SIFT cohort 3, climate survey)

They talked how they prepared after high school to become part of the science community and what they wanted to know. They told me to explore different possibilities in research with the environment and that you could always find your calling if you look for your passion. (SIFT cohort 4, research project reflection)

Support for Having the opportunity to be part of such interesting work as a high school student has been very exciting and career path inspirational. If I had to mention the biggest highlight, I would have to say that working alongside with experienced, knowledgeable mentors is very fulfilling. Being able to ask any number of questions at any given time has helped me to gain a better understanding of the projects in which I have been part of. Which has led me to want to become more involved with future research projects. (TERF cohort 3, climate survey)

They gave me advice while I was there and still do when I ask. I know I can count on them to always be helpful and answer any question I have. (SIFT cohort 2, alumni follow-up climate survey)

Sense of It's had a huge impact on my life, it allowed me to network and meet people outside of my school that are as community into field research as me. (SIFT cohort 2, alumni follow-up climate survey)

I have learned that a biological research community is always helping each other, and work will vary day to day. (TERF cohort 1, climate survey)

The level of support I gained from both SIFT and TERF is incredible. Whereas before I was an English junky, I never really considered science for a career. From the very first day of SIFT, after being immersed with individuals who had such a passion for science and were willing to share that passion with me, I felt so welcomed into the field. The astounding part of TERF was in the sense of community I felt at [the field station]. Still a little unsure of science as a potential career, I was worried I might feel rejected from all of the researchers, grads, and undergrads, but it turned out to be exactly the opposite. I now have a network of people who keep me informed about opportunities and who are just there to talk to, allowing for me to feel exceptionally more confident with science than I've ever felt with any other area. (TERF cohort 2, climate survey) 
Our research indicates the exploratory experiences in SIFT helped precollege youth clarify their thinking about environmental science careers. As SIFT participants were selected based, in part, on their existing environmental science interest, initially high levels of interest limited where change scores could go (Stake and Mares, 2001). But it is clear that their perspectives became more aligned with reality. Initially high interest slightly decreased as the day-to-day details of fieldwork were experienced; but this did not reflect an abandonment of interest, just tempering. Perception of some barriers was affected by real-world experience; confidence in environmental science practices was strengthened; and importantly, new self-knowledge gained during SIFT revealed whether or not this career direction was viable. The SIFT participation experience likely affected the frame of reference for gauging personal interests and abilities (Stake and Mares, 2001).

\section{Participation in SIFT Had Differing Effects for Youth Who Went on to TERF}

SIFT and TERF are partnered programs that provide two stages of career exploration, with the experience during the first stage likely influencing continuation to the second. Some youth ended their participation after SIFT (SIFT-only), while others went on to TERF (future-TERF). Did these two groups have a measurably different experience during SIFT?

If factors A1 and A2 are considered together, both SIFT-only and future-TERF youth started out at similarly high levels of interest in scientific activities, whether indoor or outdoor. And both started out with slightly higher interest in outdoor practices (field vs. lab). Once these two groups moved into the second part of SIFT (working directly with scientists on projects in the field), the SIFT-only youth declined in interest, while future-TERF youth held steady. For factor A3, the SIFT-only youth declined in their interest in deep thinking about environmental science, especially after the program midpoint. The future-TERF participants' interest also declined slightly, but then slightly increased after the SIFT program midpoint, such that their overall decline in interest was much less than that of the SIFT-only youth. Doing real work with scientists during SIFT appears to be important. For some, this diminished interest in continuing to explore environmental science activities, while for others, it sustained interest. The reality of the scientific fieldwork experience was critical (pattern code: reality of scientific fieldwork).

\footnotetext{
"While I do enjoy science and performing research, some of the conditions (weather or physical labor) which surround environmental field research make it somewhat less attractive than say laboratory research." (SIFT-only cohort 3, research project reflection)

"I learned that despite the changes in weather/climate/circumstances you still can have fun and learn a lot in what you do. It made me consider a career in something field research related more, although it does have its challenges." (FutureTERF cohort 3, research project reflection)
}

Both SIFT-only and future-TERF participants grew in confidence in their indoor (B1) and outdoor (B2) scientific practices after the first part of SIFT (training week). But, once again, the groups differed in confidence levels after the second part of the program. For SIFT-only youth, confidence dropped back to levels similar to preprogram, while future-TERF youth remained at the same level of confidence for indoor practices and dropped just slightly for outdoor practices. The difference between the two groups for change in outdoor practices confidence level (B2) was significant, with future-TERF youth reporting higher confidence over time. We expected that participation in the SIFT experiential training week would increase confidence in scientific practices. However, continuing on to authentic work opportunities with field scientists affected the two groups differently. SIFT-only youth lost some confidence in practices, while future-TERF youth were able to sustain their confidence after working with scientists.

\begin{abstract}
"I learned that I need to get better at sorting and classifying if I want to do this in my future." (SIFT-only cohort 4, research project reflection)
\end{abstract}

\begin{abstract}
"I learned that I struggled a little with the memory of the different plant names which would lead me away from that career." (SIFT-only cohort 4, research project reflection)

"I proved to myself that I'm capable of doing fieldwork." (Future-TERF cohort 2, research project reflection)

"I am really surprised by the simplicity of it. You would think that 'field research' implies that it has to be really difficult, but it can be something anyone can do." (Future-TERF cohort 2, research project reflection)
\end{abstract}

Change in factor D1 differed between the two groups. SIFTonly youth placed more importance on basic employment items (e.g., getting a job offer quickly, making a good salary, earning respect, having high employment demand), while future-TERF youth reported lower importance of these over time.

"So far I'm still caught in the middle on whether I want to do field research or not. All these projects I've done make me want to do field research more and more but there's more things to weigh in than just my wants." (SIFT-only cohort 4, research project reflection)

"I was led further away from making a decision toward an environmentally based job, because I feel that the work is tedious and not necessarily rewarding when it comes to respect, pay, or enjoyment of the work." (SIFT-only cohort 3 , research project reflection)

The importance of deeper meaning and intangible career benefits (factor D2) went slightly up and then down for both groups, but future-TERF youth reported overall lower importance in this area across all time points. Again, the midpoint of SIFT was key. Once the youth had time with scientists in the field, factor D2 scores went down. We cannot fully explain this result. However, it is possible that they found that intangible career benefits were harder to obtain in the reality of fieldwork than they thought. Future-TERF youth scores were lower than SIFT-only youth across all time points. And while this might indicate that having satisfying and exciting work that makes a difference was less important for them, it could also 
be indicative of a stronger commitment to a research career path despite new understanding that it might not be exciting all the time (emergent themes: commitment to this type of work, research importance, making a difference).

\begin{abstract}
"By seeing how long these researchers have worked with surveying the snails, it really showed me that a person must really enjoy what they're working with in order to make such a commitment to this project." (Future-TERF cohort 2, research project reflection)
\end{abstract}

\begin{abstract}
"She [field research scientist] talked about how at different steps in the research they have to do different things. Sometimes the work is exciting and sometimes it is boring, but it is always hard, yet interesting, work." (SIFT-only cohort 4, research project reflection)
\end{abstract}

"I learned that it is sometimes tiring to do the same work for hours at a time but I realize it is a necessary component of field research and I do not believe it will deter me from pursuing a career in environmental field research." (Future-TERF cohort 4 , research project reflection)

SIFT-only and future-TERF participants showed no significant change in perception of personal barriers to pursuit of an environmental science career (factor F1) and parallel significant change (up then down) in perception of financial barriers (factor F3). However, there was a slight difference related to perception of external barriers (factor F2, e.g., lack of social support system, conflicting commitment to raising a family, and lack of comfort working outdoors). Both groups showed no significant change and very low mean scores, which could indicate little perception of certain types of barriers. But, as the future-TERFers had significantly lower external barrier perception in comparison with SIFT-only youth, additional research examining specific types of external barriers and potential interventions to remove or mitigate such barriers seems warranted.

During SIFT, future-TERFers were more confident in their ability to perform environmental science activities and were more open to whether their future career work needed to have good pay and respect or satisfaction and excitement. When combined with their lower perception of external barriers to pursuit of an environmental science career, it makes sense that these youth wanted to continue on to the next program in the two-stage apprenticeship pathway of SIFT and TERF. Participation in SIFT may have quite effectively separated out the SIFTonly youth from the future-TERFers.

Even short-term extracurricular work with scientists can support the persistence of precollege youth interest in science careers (Aschbacher et al., 2010). The differences we found between the SIFT-only and future-TERF youth during SIFT indicate a critical split in the youth experience when the program changed from exploratory educational training to actual fieldwork with scientists. How this transition was handled by different participants was likely very important for their potential persistence in the two-stage pathway and needs further research. For example, underrepresented ethnic minority and female participants may have experienced the transition differently than majority males. Also, some urban youth who were okay with educational activities in an accessible nature reserve setting might have had significant reservations when perform- ing work in unmanaged and remote research sites. Gender and ethnicity are important influences on persistence in the STEM career pathway (Quimby et al., 2007a,b; Aschbacher et al., 2010), and our continuing research will explore these differences.

\section{Participation in TERF Provided Important Deeper Relationships}

The results discussed above indicate that youth who went on to TERF experienced SIFT slightly differently from their SIFTonly peers. But what happened for them after a more extended and immersive apprenticeship experience in environmental research? TERF provides for development of deeper relationships with multiple levels of scientists, and we expected that this could have a transformational effect that would be reflected in the final time point of the environmental science careers interest survey.

Similarly to during SIFT, interest in general science indoor and environmental science outdoor practices (factors A1 and A2) went down slightly, although ending at somewhat high levels. Again, we reason this is due to the youth gaining a better understanding of what participation in these activities actually entailed (pattern code: reality of scientific fieldwork). The excitement about participating in real research activities decreased as those activities became repetitious (emergent theme: monotony). However, TERFers reported that they learned strategies to deal with this and they learned that what gets scientists past this monotony is an understanding of what the data may show about a bigger environmental problem it might help to solve (pattern code: view of bigger picture; emergent themes: research importance, making a difference). There was no significant change in interest in deep thinking about environmental science (factor A3) or confidence in science practices (factors B1 and B2). So while TERFers' interest in scientific practices did decrease over the course of both SIFT and TERF, they still maintained a high interest in thinking about environmental science (A3 $\bar{x}=4.38$ over four time points) and high levels of confidence in doing science (B1 $\bar{x}=4.40$ and B2 $\bar{x}=4.59$ over four time points).

\footnotetext{
"Monotony in field biology would lead me away from a future career, yet the satisfaction of results would lead me toward a career." (SIFT+TERF cohort 3, TERF climate survey)

"Field science is difficult. It's not just observing and being outside. There's a considerable amount of lab work involved as well. Also it's not that exciting most of the time. The work is very meticulous and repetitive. But that is both a blessing and a curse. There is a fight against boredom at times, but because it is meticulous work, I became more acquainted with my work because I worked so closely with my data." (SIFT+TERF cohort 1 , TERF climate survey)
}

The drop in financial barrier perception (factor F3) at the final time point leads us to suspect that the longer-term relationships with scientists during TERF allowed for conversations about finances that might not have been possible during the 1-day work experiences in SIFT. As various levels of scientists shared how they got through financial barriers, this issue lost significance for the youth. New knowledge of scholarships, internships, fellowships, and research funding sources made the career appear more feasible (pattern code: 
relationships with professionals; emergent theme: informs career path).

\footnotetext{
"The advice they gave concerning how they achieved the position they were in really helped my outlook on my own options and goals." (SIFT+TERF cohort 2 participant, TERF climate survey)
}

As the youth progressed through SIFT and TERF, their agreement that an environmental science career path would include some key relationships increased. Factors H2 (having a mentor and peers with similar interests) and H3 (having an inspirational model) ended at levels higher than those found at the end of SIFT for any group. The youth liked what they experienced in a multilevel community of scientists who worked together to support each other in their career pursuit (pattern code: relationships with professionals; emergent themes: informs career path, support for career path).

\begin{abstract}
"The SIFT and TERF mentors took the time to get to know me and understand my interests in life. By them doing this, they were able to advise me on my career path. They gave me the resources I needed to continue to advance along this path. They were very inspirational to me by sharing their experiences in their own careers." (SIFT+TERF cohort 2, alumni follow-up climate survey)
\end{abstract}

\begin{abstract}
"Meeting and working under [the mentor] was the single best experience of my science career because she showed me possible doorways I could take in science." (SIFT+TERF cohort 4, TERF climate survey)
\end{abstract}

For youth who continued through TERF, 11 factors showed no significant change, including eight that also showed no significant change over time during SIFT. Factors A3, B1, and B2 are discussed above, and the levels for the others indicate the youth who went on to TERF were well positioned for continuing on the environmental science career pathway. Over four time points, TERFers had high confidence in completing science degree steps (C1 $\bar{x}=8.97$ on a 10-point scale). They placed importance on career and employment basics (D1 $\bar{x}=7.61$ on a 10-point scale), although more so on deeper meaning and intangible career benefits (D2 $\bar{x}=8.97$ on a 10-point scale). And then they agreed that an environmental science degree would satisfy career and employment basics and provide some deeper meaning (E1 $\bar{x}=7.87$ on a 10-point scale). They had low perception of personal or internal barriers to pursuit of an environmental science career ( $\mathrm{F} 1 \bar{x}=1.95$ on a five-point scale) and high confidence in overcoming perceived barriers to pursuit of an environmental science career (G1 $\bar{x}=4.38$ on a five-point scale). They agreed that their pursuit of an environmental science career path would be supported by others (H1 $\bar{x}=4.29$ on a five-point scale).

When youth have work experiences with professionals within real scientific career settings, they discover excitement and ability in scientific activities, which influences the belief that they can succeed in science (Aschbacher et al., 2010). While we have shown that this happened to a certain extent during SIFT, TERF is a very different experience in career exploration in terms of intensity and community of practice, and it took the participants an important step further. Its immersive experience allowed precollege youth to maintain a high interest in thinking about environmental science and to establish long-term apprentice relationships with scientists that further informed their perceptions of the career field. TERF participants identified with these scientists and found role models, friends, and mentors to stay in contact with for support as they prepared for entrance to the college part of the career pathway.

\section{SIFT and TERF Influenced Future Directions}

Responses to the follow-up survey about education and career-oriented benefits of participation also show differences between those who only completed SIFT and those who went on to complete both SIFT and TERF. When reflecting back on their experiences, both groups placed high value on knowledge gain about environmental research, but they placed different values on other benefits of participation. SIFT-only youth placed higher value on self-oriented and somewhat immediate benefits (knowledge about self, new friends, summer income), while SIFT+TERF youth placed higher value on future career-oriented impacts of participation (career and education ideas, career and education contacts, mentors, role models). These results align with the intended progressive design of the two-stage apprenticeship model and are supported by pattern codes and emergent themes. SIFT provides an opportunity for participants to decide whether environmental field research fits them, and so benefits related to self-knowledge were found. TERF provides a deeper experience closer to real pursuit of an environmental field research career within a community of professionals, and these data support that career pathway benefits were perceived.

While participation in SIFT and SIFT+TERF was only one part of a dynamic educational process during the high school years, we suspect that participation may have influenced shifts in intended college majors. For some youth, participation may have reinforced an already strong inclination or stimulated an initial kernel of interest. For others, the program experiences helped to clarify a better understanding of what they wanted or did not want in a career, and this led them into other major pursuits. This is supported by our determination of college major category probabilities. Participants who were already predisposed to majoring in an environmental STEM discipline before SIFT were likely to stay the course after participation in just SIFT or both SIFT and TERF. For those intending to major in some other STEM field, there was a very strong probability of staying in some other STEM major (nonenvironmental) if participation ended after SIFT. However, for those same other-STEM-major-leaning youth who went on to TERF, there was some likelihood that they transferred their STEM interest into an environmentally oriented STEM major. Those who were undecided on a college major before SIFT showed quite a difference in actual college majors depending on whether they completed only SIFT or also TERF. SIFT-only undecided youth had some likelihood of declaring an environmental STEM major, but greater likelihood of choosing a nonenvironmental STEM major. SIFT+TERF youth who were undecided going into the program progression had a very strong probability of an environmental STEM major and no chance of choosing a nonenvironmental STEM major. TERF participation appears to support the shift of both STEM-inclined and undecided youth toward environmental STEM fields. 
"I decided to change my major (from engineering) to Biological Science due to my experiences in TERF." (SIFT+TERF cohort 4, alumni follow-up climate survey)

"I really did not enjoy going out into a hot itchy prairie. I found the information and skills useful, but it was definitely not going to be a career for me. It did however make me appreciate my preference for math and physics." (SIFT-only cohort 4, alumni follow-up climate survey)

"Before SIFT, I did not think I was going to major in ecology and much after, I realized that is what I wanted to do! I am on a plan to enter the field of Ecology and Conservation Biology, hopefully with a concentration in entomology. I loved many fields of science including biology, but I didn't think I was going to have a career in it. I started college thinking I was going to be an astrophysicist but I started missing the "hands on' kind of feel field biology had when I did the SIFT and TERF programs. Now I know that that is what I really want to do! SIFT and TERF gave me an insight in what was possible with a career in ecology and biology. I hopefully will be in grad school for ecology or some other form of biology. Really SIFT and TERF have been a really big influence on me." (SIFT+TERF cohort 2, alumni follow-up climate survey)

Early access to a university-based research environment and actual participation in research opened the door for these youth to pursue additional research experiences. While some SIFT participants went on to become TERF participants, others chose to explore different research experiences that may or may not have been in an environmental STEM field. It was not uncommon for some SIFT participants to desire a lab-based research experience after having tried out a field-based one. But for others, going on to TERF and additional field-based research activities was an important next step. Many TERF participants were invited to continue to work with their field research teams for additional weeks during the summer or as returning team members for the following field season, and some of these individuals continued to return to the field station as undergraduate interns. While it is not unusual for upper-level undergraduates to conduct research, SIFT and TERF alumni often started their own independent research projects earlier in their college careers. We know of at least 35 alumni of SIFT or TERF who participated in research as first- or second-year undergraduates. Of those, the majority were former TERF participants, and several returned for research at the field station, showing how newcomers can become oldtimers (Lave, 1991; Lave and Wenger, 1991). The return of youth participants to the field station for additional apprenticeship experiences indicates the apparent establishment of a local environmental biology research career pathway.

SIFT and TERF alumni indicate that early exposure to authentic research and work alongside research scientists gave them confidence to initiate contact with professors upon arrival at college (pattern code: relationships with professionals; emergent themes: informs career path, support for career path). Intimate understanding of university-based research provided many of the youth with the ability to conduct conversations about how personal interests overlapped with a professor's research agenda. Youth were encouraged to include participation in SIFT and TERF on résumés, and this may have provided positive influence on procurement of a research position during college.
"Since SIFT I have been a lot more confident when talking to professors about research, which helped me get a research position this summer!" (SIFT-only cohort 2, alumni follow-up climate survey)

"SIFT is a wonderful resume builder and I have been able to use it on many occasions to get opportunities that I may have not been able to without having participated." (SIFT-only cohort 2, alumni follow-up climate survey)

\begin{abstract}
"My SIFT and TERF experience has actually helped me a lot in my college career. My field experience helped me get a position in a biology lab as a freshman student where I was able to begin my own research on a topic that I was passionate about in TERF." (SIFT+TERF cohort 2, alumni follow-up climate survey)
\end{abstract}

\section{CONCLUSION}

Social cognitive career theory explores the interaction of personal, environmental, and behavioral influences on career development. Within this framework, Quimby et al. (2007a) provided two recommendations: 1 ) research into the influence of social cognitive variables on academic persistence and career goal attainment and 2) attention to these variables in development and testing of vocational and educational interventions in environmental science. In our study, analyses of the data from the repeated environmental science career interest survey revealed movement in specific social cognitive career variables during the course of participation in SIFT and TERF. Our results indicate that SIFT provided a structure for changes in youth thinking to occur in all three variable domains - cognitive, outcome, and contextual. TERF influenced continued changes in youth thinking within outcome and contextual variable domains. When these results are combined with the pattern codes revealed from analysis of climate survey responses from both programs, we see how SIFT and TERF provided a framework for robust career exploration (Figure 4). Participating in field research (reality of scientific fieldwork) modified interest in environmental science activities (outcome variables) and confidence and outcome expectations for following an environmental career path (cognitive variables). Working directly with scientists (relationships with professionals) influenced the cognitive variables and also the identification of role models and social supports and perception of barriers to pursuit of the career path (contextual variables). All of these were interplaying, as the two-stage apprenticeship experience provided opportunities for acquisition of self-knowledge within a clearer understanding of the bigger picture of the environmental career field.

The significant changes and refinement in youth thinking that we have documented are evidence of how well-designed apprenticeship programs can provide realistic career-exploration experiences that influence career pathway development. Precollege apprenticeships can provide more informed perspectives of a career from which youth can decide to go forward or try another direction. In our study, youth gained important self-knowledge and a deepened understanding of environmental field research during the first-stage apprenticeship program. SIFT allowed all youth participants to clarify thinking about their suitability to the career pathway, and the transition to real research work with scientists was a crucial moment. For those who found it a good fit, the second-stage TERF program 


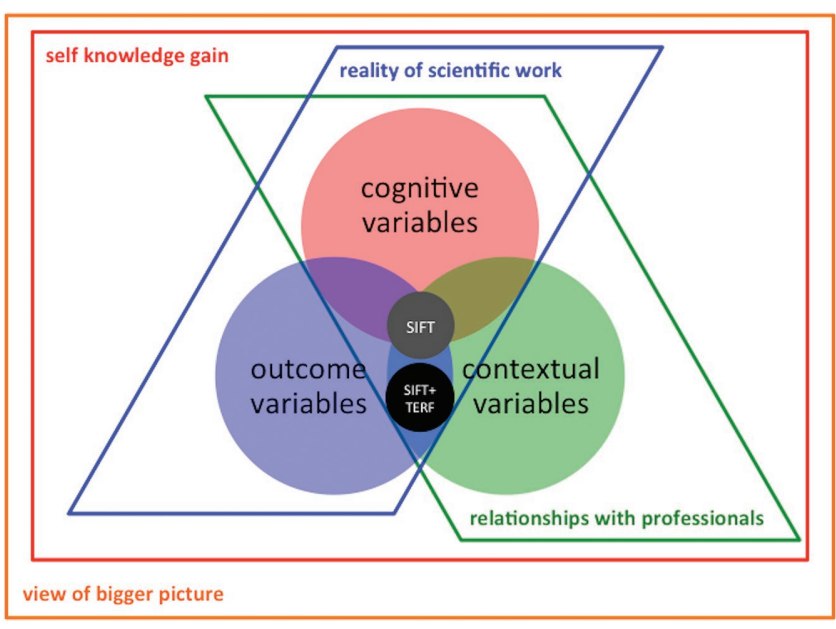

FIGURE 4. Significant changes in environmental science career interest survey factors connected to social cognitive career theory variable domains indicate participation in SIFT affected precollege youth participants in all three domains, while participation in SIFT+TERF affected participants in two domains. When emergent pattern codes from reflective climate survey responses overlay the variable domains, a framework for robust career exploration within the SIFT and TERF programs is revealed.

provided entry into a professional scientific community in which relationships with guiding role models were developed. Over the long term, some SIFTers and TERFers leveraged their experiences for further career exploration along this pathway during college. The full impact of research experience programs may be underestimated without attention to the period beyond the program experience (Stake and Mares, 2005). The follow-up measures used in our study allowed for a more complete picture of the influence of SIFT and TERF on participants during continued pursuit of their personal educational paths.

Our conclusions are based on the specific program contexts of SIFT and TERF with youth who came in with fairly high levels of interest in environmental science. The SIFT and TERF participants were competitively selected at each stage, and while our sample had a good degree of diversity (gender, ethnicity, geographic distribution across an urban-suburban-rural gradient), it may not be widely representative of precollege youth. It is possible that, rather than serving as recruitment for new youth to the career path, these apprenticeship programs provide important enrichment to keep interested youth within the pathway (Sadler et al., 2010). Some of the differences we found between SIFT-only and SIFT+TERF participants are supportive of this interpretation. However, the majority of our findings indicate the career path clarity provided by the programs was valuable regardless of whether youth continued on specifically in the environmental science research career path.

We suggest that the repeated environmental science career interest survey may be useful for assessing the influence of similar types of environmental youth programs, especially those pulling in a wide range of participants. Data can be analyzed for response patterns in participant subgroups indicating differences in certain facets of social cognitive career variable domains. These differences may suggest a need for program- matic attention to certain facets. However, we strongly suggest that additional self-reflective and open-ended survey items are necessary for a more complete picture of what is happening for youth within a program context, and follow-up measures during the postprogram period are necessary for more robust understanding of program influences.

\section{Recommendations}

Based on our study of SIFT and TERF participants, the following components appear critical for inclusion in other precollege environmental career-exploration experiences.

Ability to Approach the Next Steps and See the Big Picture. Youth come from a variety of backgrounds (urban, suburban, or rural schools, with varying experiences of their families influenced by ethnic/cultural/socioeconomic differences) and environmental career-exploration programs need to account for this. First, programs must include supports to enable youth to get beyond any discomforts created by lack of experience in the environment. In our case, the nature reserve offered easy access to wetlands, prairies, glades, and forests via managed trails for those not totally comfortable in the outdoor environment. This made entry into the field station's more secluded and rugged research sites a more feasible next step. Second, program activities must help youth find comfort and confidence in the authentic practices and culture of an environmental career. Our data indicate that a two-stage structure with exploratory (SIFT) and immersive (TERF) experiences is effective. Experiences in the first stage need to show youth potential next steps, and this can be accomplished by seeing and working with near-peers who are in the second stage. Additionally, the visibility of the hierarchy of career progression and ability to interact with all of those levels helps youth form a big picture of the career and how to get there. In our study, the big picture was of research- and restoration-focused careers at a nature reserve and university field station. We recommend that precollege youth get exposure to the specific career hierarchy in any environmentally related career-exploration program.

Reflection on the Experience. Facilitated self-reflection can provide youth with a powerful way to learn more from new experiences (Schön, 1983, 1987; Barab and Hay, 2001). In our study, participants were provided with self-reflective opportunities during repeated climate survey completion. There is no way to know how much personal deep thinking would have occurred in the absence of the climate surveys, but, as the emergent themes show, when presented with the opportunity to reflect on their experiences, participants gained self-knowledge. Reflective discussion sessions are also built into SIFT and TERF activities. An interactive reflection process with peers and led by program staff is recommended for youth to achieve deeper understanding of how they fit or do not fit within an environmental career. Having positive peer support can influence youth self-perception as future scientists (Stake and Nickens, 2005). On many occasions, we observed multiple participants articulating enthusiastic agreement ("Me, too!") after hearing a personal reflection shared by a peer. Validation of peer perceptions or experiences may be important and is not possible during personal reflection on surveys. We think it is essential that 
self-reflection not be left only to surveys but rather enhanced with face-to-face group discussion that may uncover additional thoughts.

Relationships with Professionals within a Community of Practice. We recommend youth explore environmental careers through the apprenticeship model. While youth access to professionals at multiple levels in a career pathway provides realistic views of the career at various stages and time points, within an apprenticeship framework, it allows for relationships to form. Career-exploration programs need to offer a comfortable way into a career culture that may be more foreign to some youth and also encumbered with misconceptions.

The emphasis in apprenticeship learning environments shifts from the memorization of decontextualized facts and skills described by the teacher or texts toward the appropriation of the socially contextualized practices of the community. Motivations change from obtaining grades on a test to addressing the authentic needs identified by the communities through the carrying out of "tried and true" practices. (synthesis of Lave, 1991, in Barab and Hay, 2001, p. 73)

Nature reserves and field stations are science communities in which members talk, work, and quite often eat together on a daily basis over an extended period of time. The sharing of scientific information is casual, on the fly, and as needed, specific to the task at hand. The research work takes place in a social and collaborative context. When youth participate in research apprenticeships in these communities, they engage with the community members in a similar way and become participants in the informal community culture. They do, in effect, "try on" being a scientist in the context of scientists at work. Our findings indicate that the experience of authentically trying on an environmental research career through scaffolded apprenticeship programs clarifies thinking about the fit of the career pathway. And importantly, the supportive relationships that apprenticeship fosters help youth to move forward when they find a good fit.

\section{ACKNOWLEDGMENTS}

The research reported in this paper was supported by a grant from the National Science Foundation (DRL 0739874) and by Washington University in St. Louis. We thank those who provided critical review of an earlier version of this article and Katie Westby for statistical analysis support. We greatly appreciate the support of Kim Medley, Lydia Toth, Phyllis Balcerzak, the staff at Shaw Nature Reserve, and the Tyson Research Center field station community in the development and continuation of the SIFT and TERF programs. This research was approved by the Institutional Review Board at Washington University in St. Louis (IRB 201110063).

\section{REFERENCES}

Aschbacher PR, Li E, Roth EJ (2010). Is science me? High school students identities, participation and aspirations in science, engineering, and medicine. J Res Sci Teach 47, 564-582.

Bandura A (1986). Social Foundations of Thought and Action: A Social Cognitive Theory, Englewood Cliffs, NJ: Prentice-Hall.
Barab SA, Hay K (2001). Doing science at the elbows of experts: issues related to the science apprenticeship camp. J Res Sci Teach 38, 70-102.

Bell RL, Blair LM, Crawford BA, Lederman NG (2003). Just do it? Impact of a science apprenticeship program on high school students' understandings of the nature of science and scientific inquiry. J Res Sci Teach 40, 487-509.

Bravo G, Potvin L (1991). Estimating the reliability of continuous measures with Cronbach's alpha or the intraclass correlation coefficient: toward the integration of two traditions. J Clin Epidemiol 44, 381-390.

Collins A, Brown JS, Holum A (1991). Cognitive apprenticeship: making thinking visible. Am Educ 15, 6-11, 38-46.

Collins A, Brown JS, Newman SE (1989). Cognitive apprenticeship: teaching the crafts of reading, writing, and mathematics. In: Knowing, Learning, and Instruction: Essays in Honor of Robert Glaser, ed. LB Resnick, Hillsdale, NJ: Erlbaum, 453-494.

Flowers SK, Beyer KM (2016). Early entry into ecology: authentic field research experiences for high school youth. Bull Ecol Soc Am 97, 111-122.

Garces L, Espinosa L (2013). Promoting access to undergraduate STEM education: the legal and policy environment. Bridge Linking Eng Soc 43 , $35-42$

Lautenschlager GJ (1989). A comparison of alternatives to conducting Monte Carlo analyses for determining parallel analysis criteria. Multivariate Behav Res 24, 365-395.

Lave J (1991). Situating learning in communities of practice. In: Perspectives on Socially Shared Cognition, ed. LB Resnick, JM Levine, and SD Teasley, Washington, DC: American Psychological Association, 63-82.

Lave J, Wenger E (1991). Situated Learning: Legitimate Peripheral Participation, Cambridge, UK: Cambridge University Press

Lent RW, Brown SD, Hackett G (1994). Toward a unifying social cognitive theory of career and academic interest, choice, and performance. $J$ Vocat Behav 45, 79-122.

Lent RW, Brown SD, Hackett G (2000). Contextual supports and barriers to career choice: a social cognitive analysis. J Couns Psychol 47, 36-49.

Lieber E (2009). Mixing qualitative and quantitative methods: insights into design and analysis issues. J Ethnogr Qual Res 3, 218-227.

Lincoln $Y$ (1990). The making of a constructivist: a remembrance of transformations past. In: The Paradigm Dialog, ed. EG Guba, Newbury Park, CA: Sage, 67-87.

Miles MB, Huberman AM (eds.) (1994). Qualitative Data Analysis: An Expanded Sourcebook, 2nd ed., Thousand Oaks, CA: Sage.

Packard B, Nguyen D (2003). Science career-related possible selves of adolescent girls: a longitudinal study. J Career Dev 20, 251-263.

Quimby JL, Seyala ND, Wolfson JL (2007a). Social cognitive predictors of interest in environmental science: recommendations for environmental educators. J Environ Educ 38(3), 43-52

Quimby JL, Wolfson JL, Seyala ND (2007b). Social cognitive predictors of African American adolescents' career interests. J Career Dev 33, 376394.

Richmond G, Kurth LA (1999). Moving from outside to inside: high school students' use of apprenticeships as vehicles for entering the culture and practice of science. J Res Sci Teach 36, 677-697.

Sadler TD, Burgin S, McKinney L, Ponjuan L (2010). Learning science through research apprenticeships: a critical review of the literature. J Res Sci Teach 47, 235-256

Schön DA (1983). The Reflective Practitioner: How Professionals Think in Action, New York: Basic.

Schön DA (1987). Educating the Reflective Practitioner, San Francisco: Jossey Bass

Stake JE, Mares KR (2001). Science enrichment programs for gifted high school girls and boys: predictors of program impact on science confidence and motivation. J Res Sci Teach 38, 1065-1088.

Stake JE, Mares KR (2005). Evaluating the impact of science-enrichment programs on adolescents' science motivation and confidence: the splashdown effect. J Res Sci Teach 42, 359-375.

Stake JE, Nickens SD (2005). Adolescent girls' and boys' science peer relationships and perceptions of the possible self as scientist. Sex Roles 52(1-2), 1-11. 